\title{
Lawrence Livermore National Laboratory Site Seismic Safety Program:
}

\section{Summary of Findings}

J. B. Savy and W. Foxall

U.S. Department of Energy

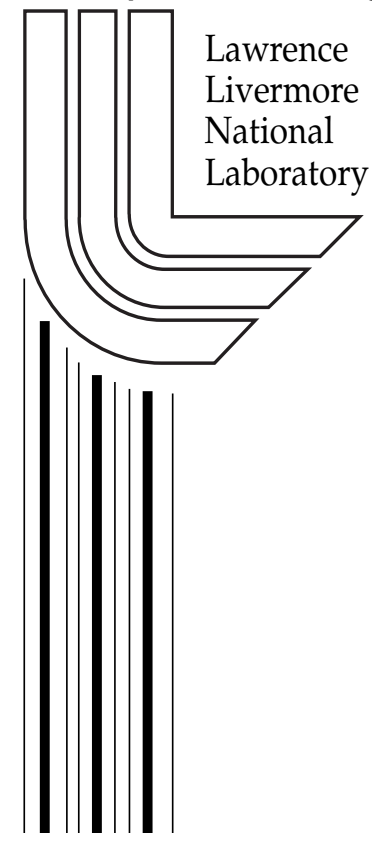

April 2002 


\section{DISCLAIMER}

This document was prepared as an account of work sponsored by an agency of the United States Government. Neither the United States Government nor the University of California nor any of their employees, makes any warranty, express or implied, or assumes any legal liability or responsibility for the accuracy, completeness, or usefulness of any information, apparatus, product, or process disclosed, or represents that its use would not infringe privately owned rights. Reference herein to any specific commercial product, process, or service by trade name, trademark, manufacturer, or otherwise, does not necessarily constitute or imply its endorsement, recommendation, or favoring by the United States Government or the University of California. The views and opinions of authors expressed herein do not necessarily state or reflect those of the United States Government or the University of California, and shall not be used for advertising or product endorsement purposes.

This work was performed under the auspices of the U. S. Department of Energy by the University of California, Lawrence Livermore National Laboratory under Contract No. W-7405-Eng-48.

This report has been reproduced

directly from the best available copy.

Available to DOE and DOE contractors from the

Office of Scientific and Technical Information

P.O. Box 62, Oak Ridge, TN 37831

Prices available from (423) 576-8401

http://apollo.osti.gov/bridge/

Available to the public from the

National Technical Information Service

U.S. Department of Commerce

5285 Port Royal Rd.,

Springfield, VA 22161

http://www.ntis.gov/

OR

Lawrence Livermore National Laboratory

Technical Information Department's Digital Library

http://www.llnl.gov/tid/Library.html 
UCRL-53674 Rev. 2

\section{Lawrence Livermore National Laboratory Site Seismic Safety Program:}

\section{Summary of Findings}

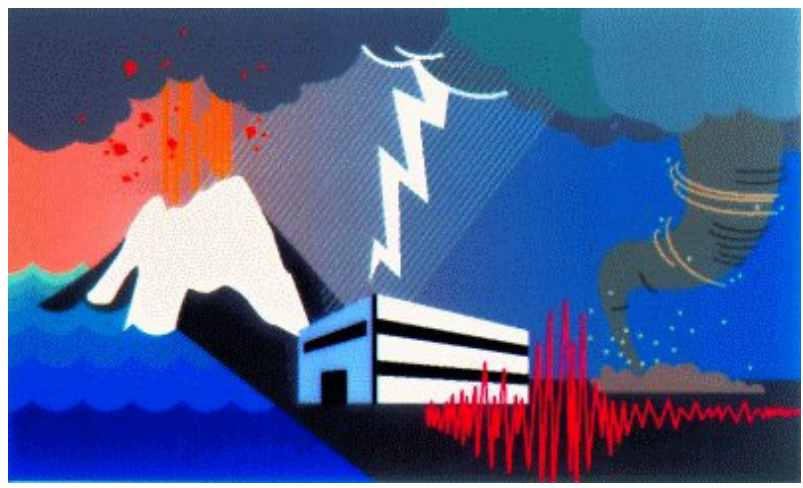

Jean Savy and Bill Foxall

\section{Hazards Mitigation Center} Lawrence Livermore National Laboratory

April 2002 



\section{Contents}

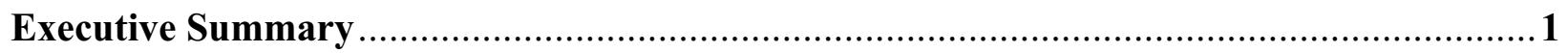

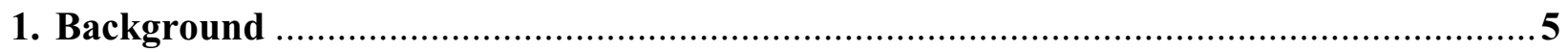

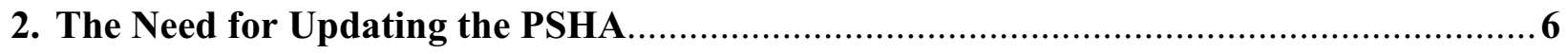

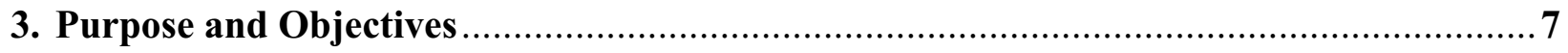

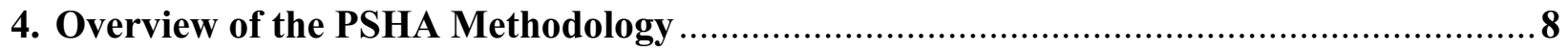

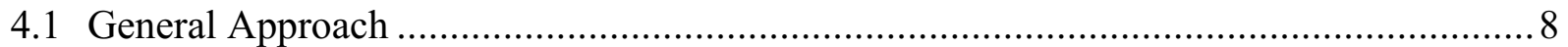

4.2 Seismic Hazard Characterization Model .............................................................. 9

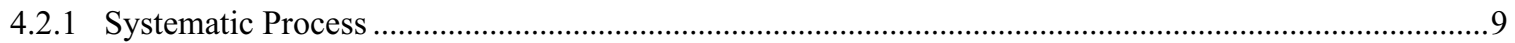

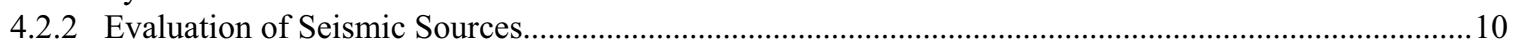

4.2.3 Assessment of Earthquake Recurrence and Maximum Magnitude.........................................................12

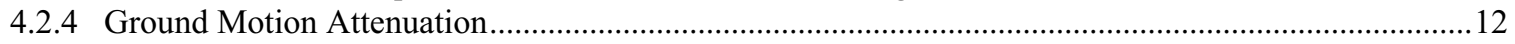

4.2.5 Mathematical Model to Calculate Seismic Hazard .............................................................................13

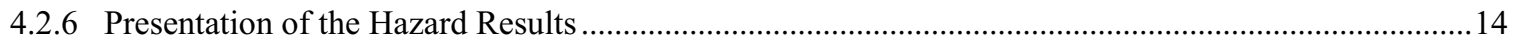

5. Characterization of the Seismic Sources ................................................................. 15

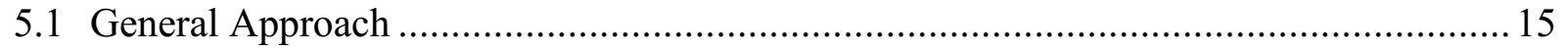

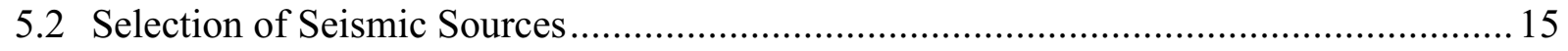

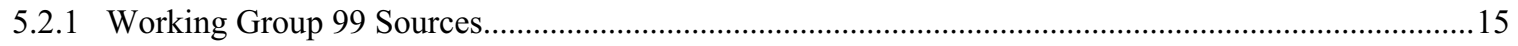

5.2.2 Local and Other Sources .............................................................................................................. 18

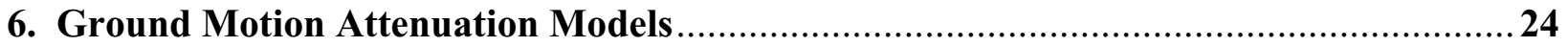

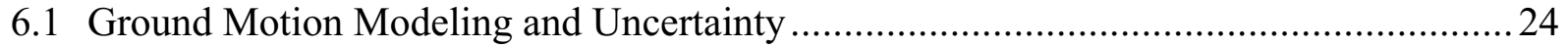

6.2 Selected Attenuation Models ......................................................................... 25

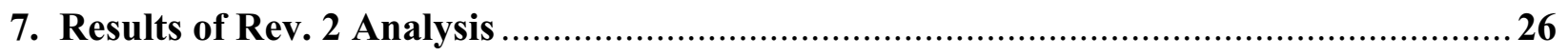

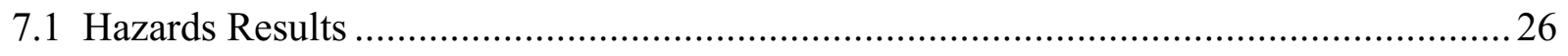

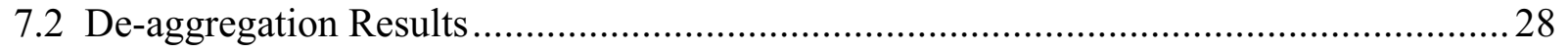

8. Comparison with Previous Results; Discussion ........................................................ 31

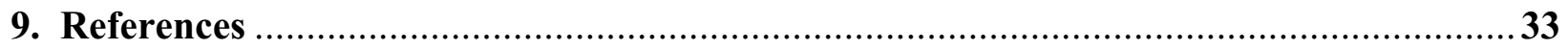




\section{List of Tables}

Table 1. WG99 earthquake source parameters.............................................................. 18

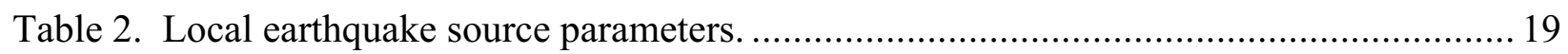

\section{List of Figures}

Figure 1. Peak ground acceleration hazard curve for LLNL site, generic soil conditions.

Figure 2. Uniform hazards spectra, 5\% damping, for LLNL generic soil conditions, for 100-, 500-, 1000-, 2000-, and 10,000-year return periods. 3

Figure 3. The four steps in the calculation of the PSHA.

Figure 4. Map of the San Francisco Bay Region showing characterization of faults of significance to seismic hazard at the LLNL site. 16

Figure 5. Map of the East San Francisco Bay Area showing characterization of active and potentially active faults in the vicinity of the LLNL site.. 17

Figure 6. California rock PGA-PSHA results for the LLNL site. ....................................... 26

Figure 7. Generic soil PGA-PSHA results for the LLNL site........................................ 27

Figure 8. Mean uniform hazard spectra for rock at the LLNL site (5\% damping). .................227

Figure 9. Mean uniform hazard spectra for generic soil at the LLNL site (5\% damping).

Figure 10. Relative contribution of the individual sources to the total

PGA-median PSHA for $500 \mathrm{~cm} / \mathrm{s} / \mathrm{s}$ and $800 \mathrm{~cm} / \mathrm{s} / \mathrm{s}$, or approximately 500 -year and 2000-year return periods. 29

Figure 11. M-D bin contributions to the 2000-year return period PGA-PSHA. 30

Figure 12. M-D bin contributions to the 2000-year return period for $1 \mathrm{~Hz}$............................ 30

Figure 13. Comparison of Rev. 1 results with Rev. 2 results for rock. ................................. 32

Figure 14. Comparison of Rev. 1 results with Rev. 2 results for soil. 32 


\section{Lawrence Livermore National Laboratory Site Seismic Safety Program: Summary of Findings}

\section{Executive Summary}

The Lawrence Livermore National Laboratory (LLNL) Site Seismic Safety Program was conceived in 1979 during the preparation of the site Draft Environmental Impact Statement. The impetus for the program came from the development of new methodologies and geologic data that affect assessments of geologic hazards at the LLNL site; it was designed to develop a new assessment of the seismic hazard to the LLNL site and LLNL employees. Secondarily, the program was also intended to provide the technical information needed to make ongoing decisions about design criteria for future construction at LLNL and about the adequacy of existing facilities. This assessment was intended to be of the highest technical quality and to make use of the most recent and accepted hazard assessment methodologies.

The basic purposes and objectives of the current revision are similar to those of the previous studies. Although all the data and experience assembled in the previous studies were utilized to their fullest, the large quantity of new information and new methodologies led to the formation of a new team that includes LLNL staff and outside consultants from academia and private consulting firms. A peer-review panel composed of individuals from academia (A. Cornell, Stanford University), the Department of Energy (DOE; Jeff Kimball), and consulting (Kevin Coppersmith), provided review and guidance. This panel was involved from the beginning of the project in a "participatory" type of review. The Senior Seismic Hazard Analysis Committee (SSHAC, a committee sponsored by the U.S. Nuclear Regulatory Commission, DOE, and the Electric Power Research Institute) strongly recommends the use of participatory reviews, in which the reviewers follow the progress of a project from the beginning, rather than waiting until the end to provide comments (Budnitz et al., 1997).

Following the requirements for probabilistic seismic hazard analysis (PSHA) stipulated in the DOE standard DOE-STD-1023-95, a special effort was made to identify and quantify all types of uncertainties. The final seismic hazard estimates were de-aggregated to determine the contribution of all the seismic sources as well as the relative contributions of potential future earthquakes in terms of their magnitudes and distances from the site.

It was found that, in agreement with previous studies, the Greenville Fault system contributes the most to the estimate of the seismic hazard expressed in terms of the probability of exceedance of 
the peak ground acceleration (PGA) at the center of the LLNL site (i.e., at high frequencies). It is followed closely by the Calaveras and Corral Hollow faults. The Mount Diablo thrust and the Springtown and Livermore faults were not considered in the hazard calculations in the 1991 study. In this study they contributed together approximately as much as the Greenville fault. At lower frequencies, more distant faults such as the Hayward and San Andreas faults begin to appear as substantial contributors to the total hazard.

The results of this revision are presented in Figures 1 and 2. Figure 1 shows the estimated mean hazard curve in terms of the annual probability of exceedance of the peak ground acceleration (average of the two horizontal orthogonal components) at the LLNL site, assuming that the local site conditions are similar to those of a generic soil. Figure 2 shows the results in terms of the uniform hazard spectra (pseudo-spectral accelerations for 5\% damping) for five return periods.

Although this latest revision is based on a completely independent and in many respects very different set of data and methodology from the previous one, it gives essentially the same results for the prediction of the peak ground acceleration (PGA), albeit with a reduced uncertainty.

The Greenville fault being a dominant contributor to the hazard, a field investigation was performed to better characterize the probability distribution of the rate of slip on the fault. Samples were collected from a trench located on the northern segment of the Greenville fault, and are in the process of being dated at the LLNL Center for Acceleration Mass Spectrometry (CAMS) using carbon-14. Preliminary results from the dating corroborate the range of values used in the hazard calculations. A final update after completion and qualification (quality assurance) of the date measurements, in the near future, will finalize the distribution of this important parameter, probably using Bayesian updating. 


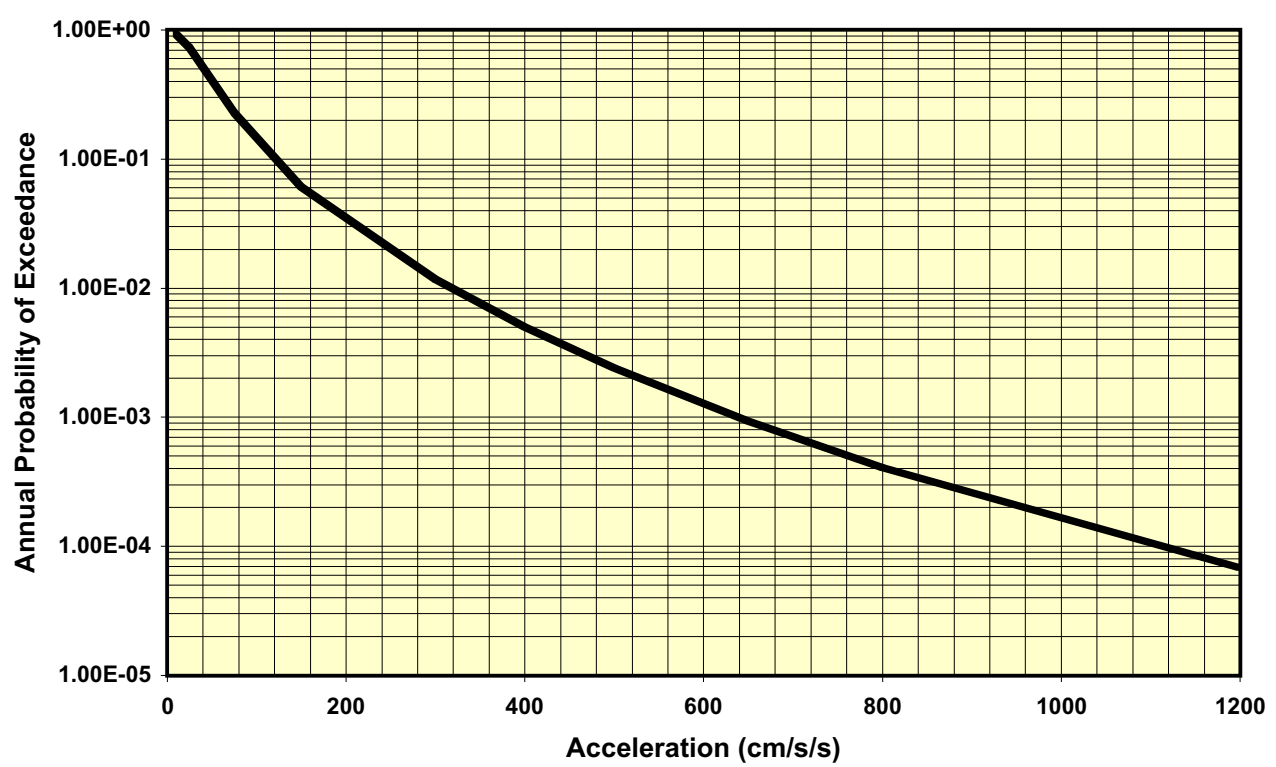

Figure 1. Peak ground acceleration hazard curve for LLNL site, generic soil conditions.

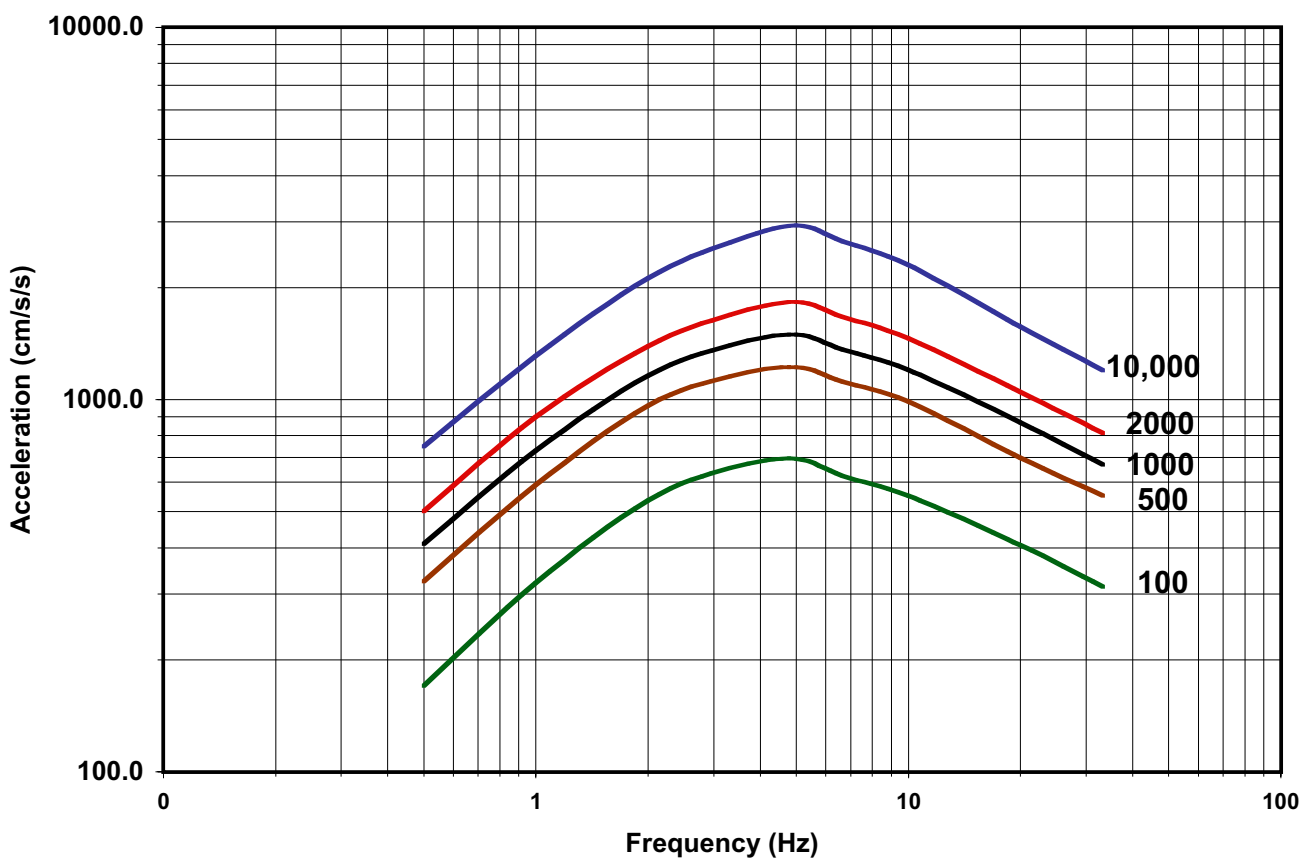

Figure 2. Uniform hazards spectra, $5 \%$ damping, for LLNL generic soil conditions, for 100-, 500-, 1000-, 2000-, and 10,000-year return periods. 


\section{Background}

This report summarizes the latest assessment of seismic hazard at the Lawrence Livermore National Laboratory (LLNL), and includes a revision of the estimate of peak ground acceleration (PGA) and peak ground spectral velocity (PGV) to be used for design and evaluation of facilities at the site.

The last such update (Scheimer et al., 1991) was based on knowledge, technology, and methodologies that had been developed in the late 1970s. The current revision (Rev. 2) is based on the most recent information on the geology and tectonics of the region. It benefits from the results of recent and ongoing studies of earthquake potential in the San Francisco Bay Region (SFBR) performed by the United States Geological Survey (USGS) and other agencies, and fault modeling approaches developed by LLNL jointly with the Southern California Earthquake Center (SCEC). This update follows the most recent methodology for performing probabilistic seismic hazard analysis, as recommended in the Department of Energy (DOE) standards (1020 Series) and documented in NUREG/CR-6372, Recommendation for Probabilistic Seismic Hazard Analysis: Guidance on Uncertainty and Use of Experts (Budnitz et al., 1997).

The major improvement over the previous estimates is a clear and rational identification and quantification of the uncertainties, both random (aleatory) and due to lack of knowledge (epistemic).

A large amount of information on the sources of earthquakes in the SFBR has been generated by studies sponsored by the USGS and other agencies in the last few years, including the Working Group 99 on California Earthquake Probabilities (WG99). The new information provided by these studies formed the basis for improved characterization of earthquake sources of significance to seismic hazard at the LLNL site and the associated uncertainties.

The results are de-aggregated to show the relative contribution of each of the seismic sources considered in the hazard model. This operation shows that the Greenville Fault system dominates these new seismic estimates, followed by the Calaveras and the Corral Hollow faults systems; then, by an order of magnitude less, it is followed by the Springtown and Mount Diablo thrust, and finally by the Las Positas Fault. Although these new estimates are the result of a completely new and independent analysis, the differences between the new mean hazard curves and those of the 1991 study appear to be statistically insignificant. 


\section{The Need for Updating the PSHA}

In general, estimation of seismic hazard is based not only on our understanding of the regional tectonics and detailed characterization of the faults in the area but also on the analysis methods employed and the types of physical and empirical models that are deemed appropriate for the analysis. Recognizing that our understanding of the seismic environment and the methods of analysis change continuously, the DOE, in its latest standards, gives specific guidance on the need for re-evaluating the PSHA at a DOE site. DOE Order 420.1 and Standard DOE/STD-1020 stipulate that hazard estimates should be re-evaluated at least every 10 years and an update should be performed if there are new findings relative to the seismic environment.

Several studies during the past 10 years have provided a wealth of new information on the geometries and recurrence rates of active faults in the SFBR. These include a region-wide study commissioned by the California Department of Transportation and a major effort by the WG99 led by the USGS (WGCEP, in preparation, 2002). In particular, a new structural model for the Livermore Valley and adjacent areas has recently been proposed (Unruh and Sawyer, 1997). LLNL has been a leading participant in WG99 by providing a member to the overview panel. In addition, LLNL collaborated with William Lettis and Associates, Piedmont Geophysical, and the USGS in the detailed characterization of the Greenville Fault by providing age dating of samples used to estimate the slip rate on the fault.

LLNL has been collecting seismicity data on its seismic network for the last 20 years. Analysis of the three-dimensional spatial distribution of the small earthquakes recorded by this network contributes to the characterization of earthquake sources in the vicinity of LLNL. Approximately 900 events having magnitudes up to M4.5 have been recorded since 1983.

Finally, the methodology recommended by DOE emphasizes estimation of the uncertainty, as described in an earlier study by the Senior Seismic Hazard Analysis Committee (SSHAC, Budnitz et al., 1997). The new data allow us to identify alternative candidate models that are at the core of the representation of the uncertainty in the PSHA . 


\section{Purpose and Objectives}

The LLNL Site Seismic Safety Program was conceived in 1979 during the preparation of the site Draft Environmental Impact Statement. The impetus for the program came from the development of new methodologies and geologic data that affect assessments of geologic hazards at the LLNL site. The Site Seismic Safety Program was designed to develop a new assessment of the seismic hazard to the LLNL site and LLNL employees. Secondarily, the program was also intended to provide the technical information needed to make ongoing decisions about design criteria for future construction at LLNL and about the adequacy of existing facilities. This assessment was intended to be of the highest technical quality and to make use of the most recent and accepted hazard assessment methodologies. The technical work was to be done by the best available personnel, either already part of the LLNL staff or available to LLNL on a consulting basis.

The basic purposes and objectives of the present revision are similar to those of the previous studies. Although all the data and experience assembled in the previous studies were utilized to their fullest, the large quantity of new information and new methodologies led to the formation of a new team that includes LLNL staff and outside consultants from academia and private consulting firms. A peer-review panel composed of individuals from academia (A. Cornell, Stanford University), DOE (Jeff Kimball), and consulting (Kevin Coppersmith) provide review and guidance. This panel was involved from the beginning of the project in a "participatory" type of review. Among the various types of reviews that can be implemented, the SSHAC (Budnitz et al., 1997) strongly recommends the use of participatory reviews, in which the reviewers follow the progress of a project from the beginning, rather than waiting until the end to provide comments.

Following the requirements for PSHA stipulated in the DOE standard DOE-STD-1023-95, a special effort was made to identify and quantify all types of uncertainties. The final seismic hazard estimates were de-aggregated to determine the contribution of all the seismic sources as well as the relative contributions of potential future earthquakes as a function of their magnitudes and distances from the site. 


\section{Overview of the PSHA Methodology}

\subsection{General Approach}

The methodology used to assess seismic hazards and the associated uncertainty at the LLNL site must provide technically sound results that meet the regulatory requirements, are amenable to regulatory review, and make appropriate use of site characterization data. To meet these goals, the methodology employed incorporates the following attributes:

(1) Experience-based. The methodology takes advantage of the experience gained from recent seismic hazard analyses. Over the past decade, probabilistic methods have evolved into the generally preferred state-of-the-art for assessing vibratory ground motion at critical facilities. By incorporating recurrence information and input variability, these methods provide a more complete evaluation of hazard for risk-based design, long-term performance assessment, and regulatory review than do deterministic methods. Recent applications of probabilistic methodologies, associated lessons learned, and ongoing evaluations and integration of seismic hazard methodologies (e.g., the SSHAC study [Budnitz et al., 1997], jointly sponsored by the DOE, the NRC, and the Electric Power Research Institute) provide the basis for the methodology described in this report.

(2) Data-driven. Development of inputs to the seismic hazard methodology and the associated input variability (uncertainty) is based on source-specific data. The methodology is capable of incorporating all relevant source-specific data available, including information on earthquake recurrence. The methodology also allows seismic hazard assessments to be easily updated as new data become available.

(3) Proper treatment of uncertainties. The methodology provides an unbiased assessment of seismic hazards by incorporating and properly treating various types of input variability. These types of variability include uncertainty in data interpretations and randomness in the earthquake process. The uncertainty is directly incorporated into the calculation of hazard, rather than qualitatively contributing to selection of a deterministic value. This facilitates regulatory decision-making and risk-based design. The methodology accommodates alternative relationships describing physical processes (i.e., earthquake occurrence), alternative values of parameters associated with those relationships (e.g., fault dip, slip rates, and maximum magnitudes), and alternative seismic source characterizations based on different interpretations of the available data.

(4) Flexible. The methodology accommodates a range of credible scientific interpretations, approaches, and data. Further, the methodology allows rational consideration of unlikely or highly uncertain scenarios. For example, the methodology accommodates the notion of seismic sources occurring in regions where faults are presently unmapped or unknown. This flexibility results from the probabilistic framework in which alternative input interpretations are explicitly incorporated. 
(5) Facilitate Sensitivity Analysis. The methodology is structured such that sensitivity analyses are facilitated. Such analyses identify important contributors to the hazard result and the relative importance of various data and interpretations. Similarly, they are used to highlight relationships or parameters for which differences in interpretation or data do not strongly influence the hazard at the site. Hence, the methodology aids in setting priorities for additional data collection and analysis efforts, so that the most important technical issues are addressed and reductions in uncertainty have the greatest impact.

To fulfill the above requirements, the present state-of-the-art approach (as described in the SSHAC report [Budnitz et al., 1997]), uses the concept of the Technical Facilitator Integrator to rationally integrate the information from a group of experts. We followed the simplified approach described by the SSHAC, in which all the criteria for performing a good PSHA are followed, albeit with a limited number of experts.

\subsection{Seismic Hazard Characterization Model}

\subsubsection{Systematic Process}

Five steps are involved in deriving the distribution of seismic hazard.

Step 1: Evaluation of seismic sources.

Determine the geometries and spatial distribution of potential sources of future seismic activity in the region around the site. Characterize the uncertainty in the spatial description of each source.

Step 2: Assessment of earthquake recurrence and maximum magnitude.

For each seismic source, describe the distribution of the rates of occurrence of future earthquakes as a function of magnitude. Estimate the maximum magnitude for each source. Characterize the uncertainty in recurrence relations and in maximum magnitude.

Step 3: Ground motion attenuation.

For the site region, evaluate or determine relations that express how the amplitudes of selected ground motion parameters vary with earthquake magnitude and source-to-site distance. Characterize the uncertainty in these ground motion/attenuation relations.

Step 4: Mathematical model to calculate seismic hazard.

Integrate over each combination of inputs determined in steps 1 through 3 to calculate a seismic hazard and plot a curve expressing the annual probability that a given value of ground motion will be exceeded. Carry out the integration for all combinations of inputs to incorporate the variability of input estimates. 
Step 5: Presentation of the hazard results.

Express the results of step 4 as a distribution of seismic hazard curves that can be represented by a mean curve and curves representing particular percentiles of the distribution.

Each of these steps is discussed below and shown schematically in Figure 3.

Step 1
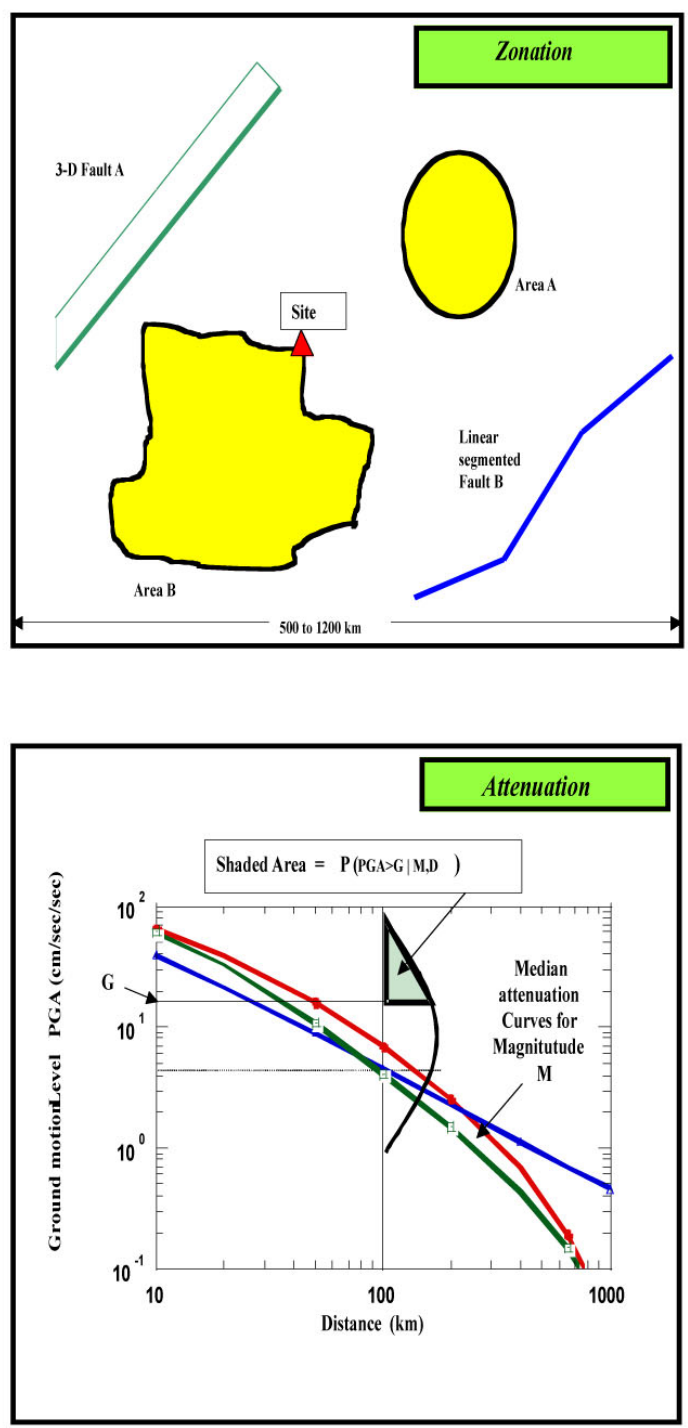

Step 3
Step 2
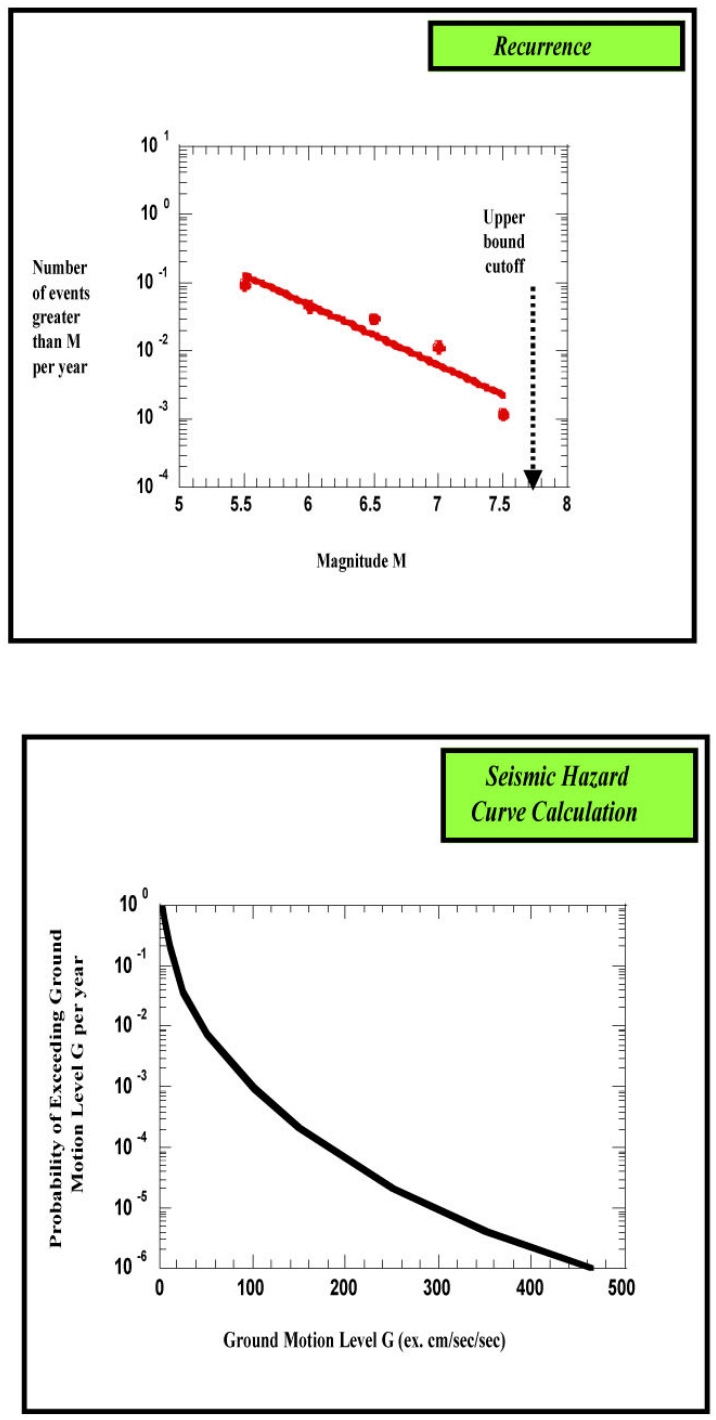

Step 4

Figure 3. The four steps in the calculation of the PSHA. 


\subsubsection{Evaluation of Seismic Sources}

A seismic source represents a portion of the earth's crust having the potential to generate future earthquakes. The assumption is made that the geological regime is stationary over the period ranging from the time of the earliest available historical data to some date in the near (geological) future, so that the probability of earthquake occurrence as a function of magnitude and the maximum magnitude associated with a given source can be considered invariant. Seismic sources include mapped or modeled faults and volumetric zones within which future earthquakes may occur but for which specific faults are not identified. Seismic waves attenuate with distance so that the magnitude of an earthquake capable of generating significant ground motion at the site increases with increasing distance. Therefore, since the dimensions of a fault govern the maximum magnitude of the earthquakes it can generate, the size of the features that need to be considered in the source characterization increases with increasing distance from the site. Similarly, the geometries of distant sources can be defined in less detail than those of more local sources. Definition of zone sources is based upon regional seismicity and tectonic characteristics. Characterization of fault sources is based upon evaluation of available geological, seismological, geophysical, and geodetic data. The characterization of each source contains the following elements:

- Segmentation model: Earthquakes often rupture only segments of their source faults and are therefore of lower magnitude than would be generated by a rupture of the entire fault. These events are often arrested by recognizable structural or other barriers to rupture propagation. Therefore, mapped features such as prominent fault bends and offsets or other structural characteristics or behavioral changes (e.g., seismicity or slip rate) are used to define segmentation points in building fault segmentation models. Successive earthquakes may behave differently, some being arrested by a given barrier and others breaking through it. This variability in behavior leads to alternative rupture scenarios for each multi-segment fault; for example, a two-segment fault (one segmentation point) can produce earthquakes that rupture either the individual segments or both segments together. The relative rates of these scenarios is governed by assigning a probability of failure to each segmentation point, based on the available data.

- Source geometry: The locations and geometries of fault segments are defined in three dimensions by the map coordinates of the upper fault tip (i.e., the fault trace in the case of surface faults), fault dip, and the upper and lower depth limits of seismogenic rupture, $\mathrm{D}_{1}$ and $\mathrm{D}_{2}$, respectively. Volumetric source zones are defined by the vertices of polygons on the Earth's surface and by the upper and lower limits of seismogenic rupture.

- Fault slip rate: Slip rates assigned to fault segment sources are derived from paleoseismic observations, where these are available. These provide estimates of geological slip rates averaged over a few to many earthquake cycles, which are generally appropriate for characterizing long-term mean earthquake recurrence rates, as described below. In active tectonic regions, such as the western United States, the assigned slip rates are constrained by the regional strain budget imposed by geodetic observations and global plate tectonic models. 
Slip rates for faults for which paleoseismic data are not available can sometimes be estimated from kinematic modeling within the same geodetic and tectonic constraints.

- Probability of activity: The overall probability that a fault is active is assigned primarily on the basis of historic observations of past earthquakes and paleoseismic evidence for late Quaternary, and particularly Holocene, events.

In general, seismic source characterization is subject to significant epistemic uncertainty, stemming typically from the sparseness of the available data. The objective of the source characterization approach is to capture the full ranges of parameter values and viable interpretations that are consistent with the data. The uncertainty distribution contains contributions from (1) The ranges of parameter values (fault length, width, dip, slip rate, segmentation point probabilities, etc.) that are permitted by the data; and (2) fundamentally different tectonic interpretations, which result not only in definition of alternative sets of sources (each with a different set of probabilities of existence) but also in different geometrical dependencies among the faults. Uncertainties in the parameters are described by assigning a simple weighted distribution to each parameter, and the full range of parameter combinations is sampled and propagated to model the uncertainty in the hazard estimates within the overall Monte Carlo routine used in the PSHA, as described later. Alternative tectonic interpretations and dependencies among the sources are described by branches of a logic tree that are input to the hazard calculation explicitly. Each branch is weighted according to the ability of that interpretation to explain the available data.

\subsubsection{Assessment of Earthquake Recurrence and Maximum Magnitude}

Each seismic source is characterized by a maximum magnitude, an earthquake recurrence model, and the uncertainties in the parameters of the model. The maximum magnitude, $\mathrm{m}^{\mathrm{u}}$, for each fault source is calculated from the fault area using a weighted distribution of alternative empirically based magnitude-area relationships. A recurrence relationship expresses the expected number of earthquakes per year having magnitudes greater than some minimum, $\mathrm{m}^{\circ}$ ( M5 in this study) and less than $\mathrm{m}^{\mathrm{u}}$. Recurrence relationships for fault sources are developed from the slip rates and segmentation point failure probabilities discussed earlier. For source zones, historical and instrumental seismicity form the primary data for characterization of maximum magnitudes and recurrence.

\subsubsection{Ground Motion Attenuation}

A ground motion attenuation function for use in PSHA is a probability density function whose parameters depend on the earthquakes and site characteristics. The standard version is a function of the earthquake magnitude of the earthquake and source distance from the site of interest (i.e., distance from the earthquake source to the LLNL site). The probability of exceeding a certain value of the ground motion caused by an earthquake of magnitude $\mathrm{M}$ and located at a distance $\mathrm{R}$ from the site is calculated by means of the ground motion attenuation functions. 


\subsubsection{Mathematical Model to Calculate Seismic Hazard}

As developed by Cornell (1968), the probabilistic hazard methodology aims to calculate the annual probabilities that various levels of ground motion (characterized as, e.g., peak horizontal ground acceleration, peak ground velocity, or peak spectral values) will be exceeded at a site. Procedures to accomplish this assessment are described by Cornell and form the basis for recent state-of-the-practice methodologies recommended for DOE facilities.

The probabilistic hazard curve represents the integration, overall earthquake sources and magnitudes, of the probability of occurrence of all possible future earthquakes, and for each earthquake, the probability that a particular value of ground motion is exceeded at the site. The current state-of-the-practice followed in this study is to represent the temporal occurrence of earthquakes as a Poisson process. The probability of earthquake occurrence as a function of magnitude is generally represented by an exponential distribution (Gutember-Richter). In the western United States, the characteristic earthquake concept (Schwartz and Coppersmith, 1984) is also often applied to individual faults for which there are sufficient data to describe their behavior (see Sections 4.2 and 5). The occurrence model we have developed combines both exponential and characteristic earthquake behavior for single- and multi-segment rupture scenarios, and is implemented using Monte Carlo simulation to derive a frequency of occurrence versus magnitude relationship for each single-segment and multi-segment source.

The Poisson probability that, at a given site, a ground motion parameter, Z, will exceed a specified value, $z$, during a specified time period, $T$, is given by the expression

$$
P(Z>z)=1.0-e^{-\eta(z) \cdot T},
$$

where $v(z)$ is the average frequency during time period $T$ when the level of ground motion parameter $Z$ exceeds $z$ at the site resulting from earthquakes from all sources in the region.

The frequency of exceedance, $v(z)$, incorporates the variability (aleatory and epistemic) in the time, size, and location of future earthquakes and variability in the level of ground motions they produce at the site. It is computed by the expression

$$
v(z)=\sum_{n=1}^{N} a_{n}\left(m^{\circ}\right) \int_{m=m^{\circ}}^{m^{\prime \prime}} \int_{r=0}^{\infty} f_{n}(m) f_{n}(r \mid m) P(Z>z \mid m, r) d r d m
$$

where

$a_{n}\left(m^{\circ}\right)$ is the frequency of earthquakes on seismic source $n$ above a minimum magnitude of engineering significance, $m^{\circ}$;

$f_{n}(m)$ is the probability density function of event size on source $n$ between $\mathrm{m}^{\circ}$ and a maximum earthquake size for the source, $m^{u}$; 
$f_{n}(r \mid m)$ is the probability density function for distance to earthquake rupture on source $n$, which may be conditional on the earthquake size; and

$P(Z>z \mid m, r)$ is the probability that, given a magnitude $m$ earthquake at a distance $r$ from the site, the ground motion exceeds a value $z$.

In practice, the double integral in Equation 2 is replaced by a double summation with the density function $f_{n}(m)$ and $f_{n}(r \mid m)$ replaced by discrete representations of their corresponding cumulative functions. As shown in Figure 3 (Step 4), the result is a hazard curve expressing the annual probability that various levels of the ground motion parameter will be exceeded.

\subsubsection{Presentation of the Hazard Results}

The basic calculation described above results in a seismic hazard estimate for a single characterization of a set of seismic sources, including recurrence and maximum magnitude values, and a single ground motion attenuation relation. Thus, the result of this calculation is a single hazard curve (Figure 3, Step 4) that represents the randomness, or aleatory uncertainty, inherent in the location and magnitude of future earthquakes, and in the generation and seismic wave propagation.

There is also uncertainty in the characterizations of seismic sources and ground motion/attenuation. This uncertainty, called epistemic uncertainty, arises from incomplete knowledge of earthquake processes, limited data, and permissible alternative interpretations of the available data. The methodology explicitly incorporates these uncertainties into the analyses to quantify the uncertainty in the final hazard results.

The Monte Carlo approach to uncertainty propagation, used in this study, makes use of multiple subjective probability distributions for the various parameters of the hazard input model parameters. The Monte Carlo simulation technique samples from these distributions and a large number of hazard curves are calculated to create an artificial data set from which statistics are performed to derive the mean and percentiles of the distribution of the hazard.

In this approach, uncertainty in seismic source zonation is represented by weighted alternative maps (in which each map represents a possible, yet weighted, realistic physical model of future seismicity); uncertainty in recurrence is characterized by subjective probability distributions on the recurrence parameters; and uncertainty in ground motion evaluations is characterized by a set of alternative ground motion relationships and their associated weights. 


\section{Characterization of the Seismic Sources}

\subsection{General Approach}

Fault geometries for the LLNL PSHA source model are constrained using available geological mapping and seismicity and geophysical data. Geologic slip rates are estimated from paleoseismic results together with fault kinematic models, within overall geodetic and tectonic plate velocity constraints. Data and interpretations were obtained by a comprehensive review of published and unpublished literature and by elicitation of several experts on SFBR geology and tectonics during several workshops and individual interviews. This process was greatly facilitated by our membership (Foxall) on the overview panel of WG99. Historical seismicity data are taken from Bakun (1999), and the USGS and UC Berkeley catalogs of instrumentally located earthquakes were obtained through the Northern California Earthquake Data Center. The LLNL seismic network provides important data for characterizing sources and recurrence close to the LLNL site, where numerous small events have occurred.

\subsection{Selection of Seismic Sources}

Figures 4 and 5 show the SFBR faults included in the source characterization model. In general, these are faults that show evidence for Holocene and late Quaternary activity that are of potential significance to hazard at the LLNL site. The sources are divided into two groups: (1) regionally significant faults that are included in the WG99 source characterization; and (2) local and other faults of significance to LLNL site hazard. Group 2 includes the Greenville Fault and Mt. Diablo thrust. These two faults are part of the WG99 characterization, but are dealt with separately and characterized in detail in the present study because of their proximity to the site. Group 2 also includes smaller or slower slip rate faults in the immediate vicinity of the site (Figure 5), and other potentially significant faults that are not included in WG99. The Ortigalita Fault is relatively long and has an estimated slip rate on the order of $1 \mathrm{~mm} / \mathrm{yr}$. However, it is distant from the site and does not make a significant contribution to the hazard, and so is not described further in this report.

\subsubsection{Working Group 99 Sources}

WG99 applied the following criteria to select fault sources for their characterization: (1) Slip rate of $1 \mathrm{~mm} / \mathrm{yr}$ or greater; and (2) capable of generating earthquakes of moment magnitude (M) 6.7 or greater. The WG99 sources (except the Greenville Fault and Mt. Diablo thrust) are shown in orange in Figures 4 and 5 and listed in Table 1. The WG99 characterizations of these faults, including derived Poissonian earthquake occurrence rates, are adopted directly for input into the PSHA. This is because the WG99 source characterizations are the result of an extensive process involving knowledge dissemination workshops and alternative characterizations and weighting 
by expert panels that involved a large proportion the scientific community knowledgeable about SFBR faulting, tectonics, and seismicity. Therefore, the WG99 source characterization models are probably the best possible consensus representation of the opinions of the informed scientific community. Note that the WG99 source characterizations shown in Figure 4 and Table 1 are preliminary as of January 2002. Finalization of the model, currently being completed by WG99, is not likely to result in changes to source geometries, but may involve revision of some of the earthquake occurrence rates. Final results are expected to be available in April 2002, and will be published as USGS Circular 1181 (WGCEP, in preparation, 2002).

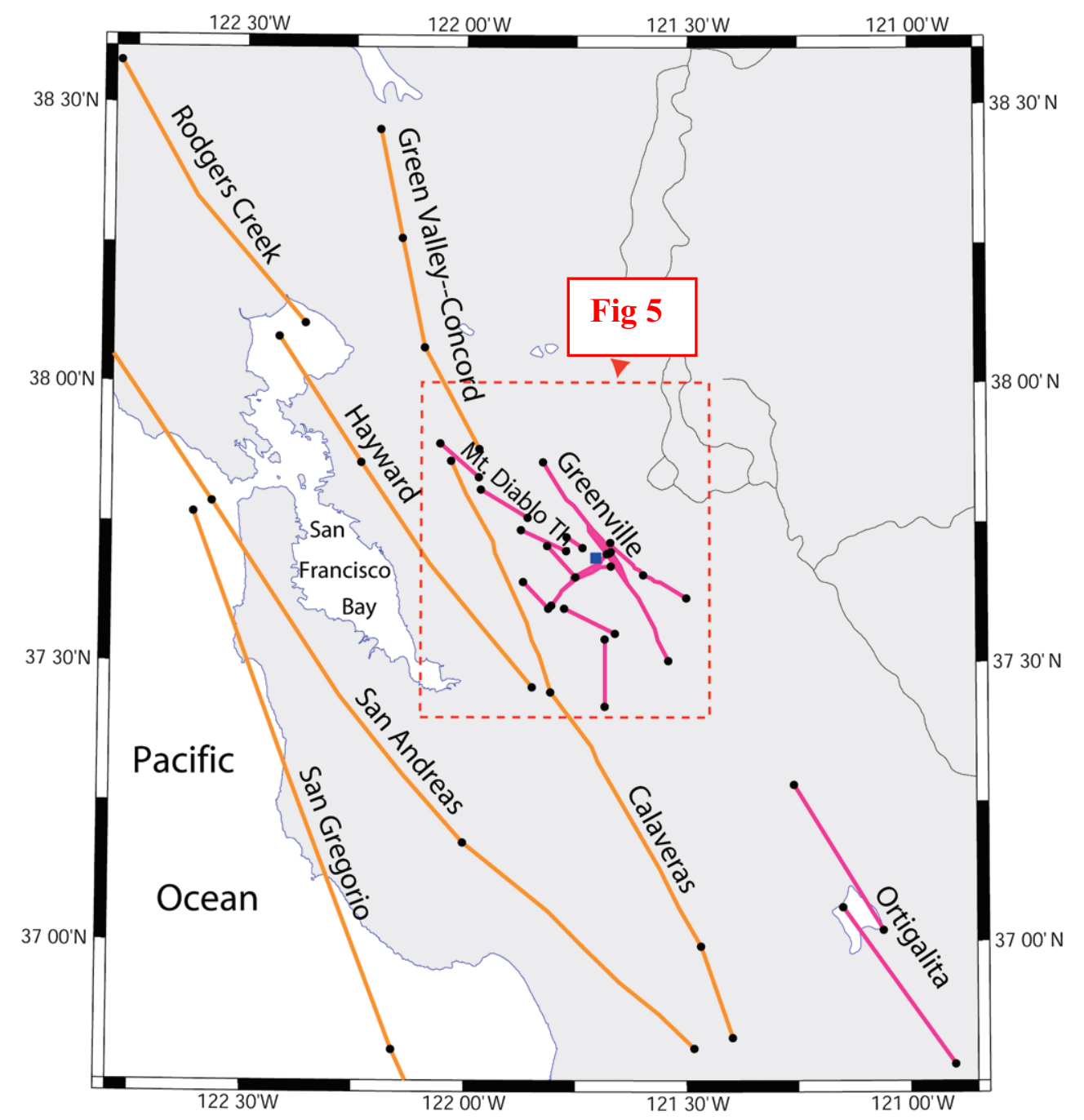

Figure 4. Map of the San Francisco Bay Region showing characterization of faults of significance to seismic hazard at the LLNL site. The LLNL site is represented by the blue square, and major right-lateral strike slip faults included in the WG99 source characterization (Schwartz et al., 2002, in preparation) are shown in orange. Significant local and other faults are shown in magenta. 


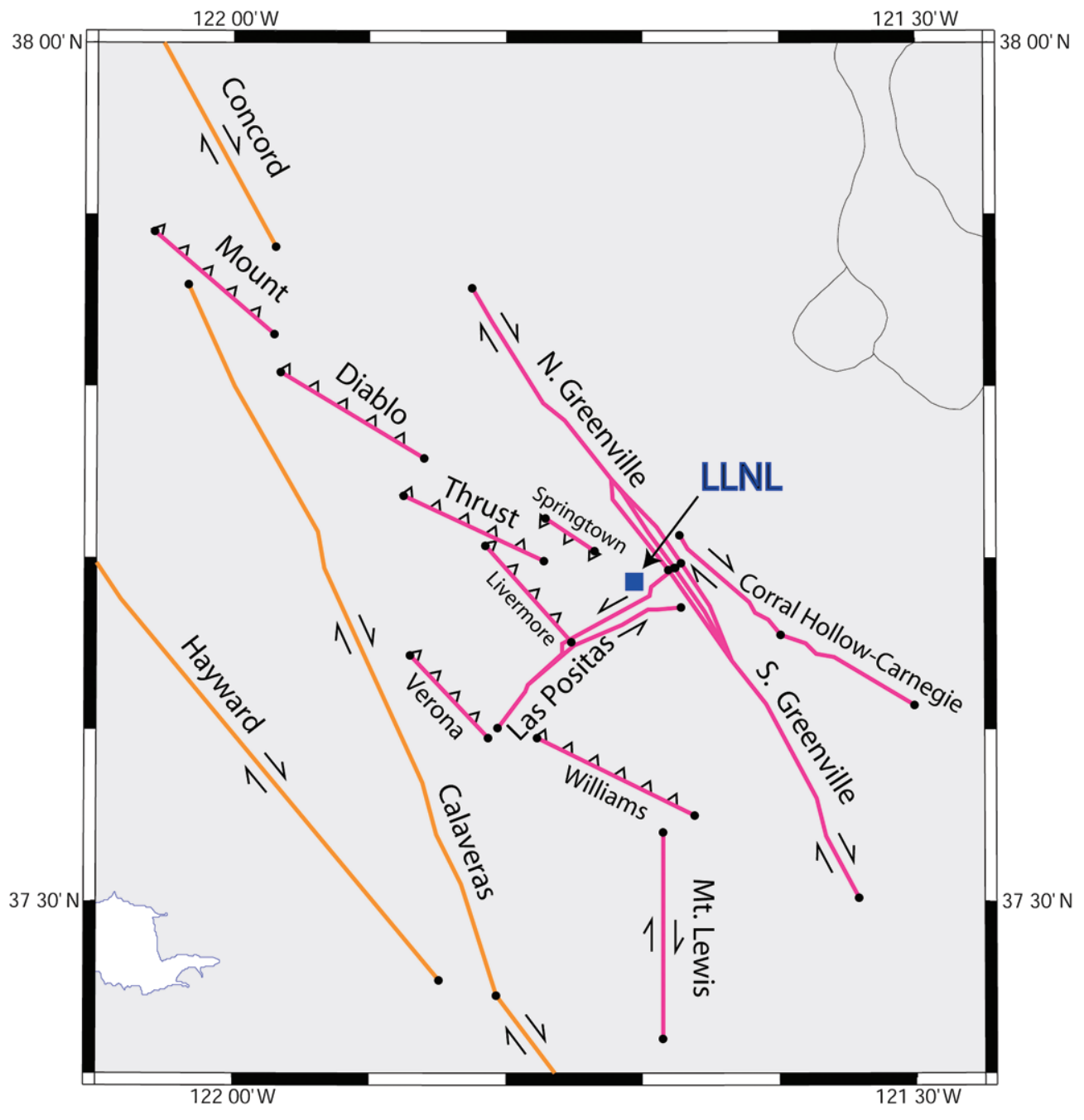

Figure 5. Map of the East San Francisco Bay Area showing characterization of active and potentially active faults in the vicinity of the LLNL site. Teeth indicate dip direction of thrust and reverse faults. Mt. Diablo thrust and Livermore Fault are blind; traces shown represent the buried upper tips of these faults. 
Table 1. WG99 earthquake source parameters.

\begin{tabular}{llccccc}
\hline \multicolumn{2}{c}{$\begin{array}{c}\text { Fault system and } \\
\text { fault segment(s) }\end{array}$} & $\begin{array}{c}\text { L } \\
(\mathbf{k m})\end{array}$ & $\begin{array}{c}\mathbf{D}_{1} \\
(\mathbf{k m})\end{array}$ & $\begin{array}{c}\mathbf{D}_{2}^{(2)} \\
(\mathbf{k m})\end{array}$ & $\begin{array}{c}\mathbf{D i p}^{(3)} \\
(\mathbf{d e g})\end{array}$ & $\begin{array}{c}\mathbf{V} \\
(\mathbf{m m} / \mathbf{y r})\end{array}$ \\
\hline San Andreas: & Offshore & $144 \pm 21^{(1)}$ & 0 & 11 & 90 & $24 \pm 3$ \\
& N. Coast & $182 \pm 20$ & 0 & 11 & 90 & $24 \pm 3$ \\
& Peninsular & $85 \pm 25$ & 0 & 13 & 90 & $17 \pm 4$ \\
& Santa Cruz & $62 \pm 15$ & 0 & 15 & 90 & $17 \pm 4$ \\
Rodgers Creek & & $63 \pm 10$ & 0 & 12 & 90 & $9 \pm 2$ \\
Hayward: & North & $30 \pm 15$ & 0 & 12 & 90 & $9 \pm 2$ \\
& South & $55 \pm 18$ & 0 & 12 & 90 & $9 \pm 2$ \\
Calaveras: & North & $50 \pm 10$ & 0 & 13 & 90 & $6 \pm 2$ \\
& Central & $59 \pm 10$ & 0 & 11 & 90 & $15 \pm 3$ \\
& South & $19 \pm 10$ & 0 & 11 & 90 & $15 \pm 3$ \\
Green-Valley: & North & $22 \pm 8$ & 0 & 14 & 90 & $5 \pm 3$ \\
& South & $22 \pm 6$ & 0 & 14 & 90 & $5 \pm 3$ \\
Concord & & $22 \pm 8$ & 0 & 16 & 90 & $4 \pm 2$ \\
San Gregorio: & North & $115 \pm 25$ & 0 & 13 & 90 & $7 \pm 3$ \\
& South & $79 \pm 20$ & 0 & 12 & 90 & $3 \pm 2$ \\
\hline
\end{tabular}

(1) Quoted uncertainties are nominal 2 standard deviation values.

(2) Lower limit of seismogenic rupture based on seismicity and heat flow data.

(3) Dip uncertainties not assigned by WG99.

\subsubsection{Local and Other Sources}

Greenville Fault: The Greenville fault is the easternmost member of the NW-striking rightlateral San Andreas fault system in the SFBR. Although, based on data presently available, it is considered to have the lowest slip rate of the faults of this system, it makes the largest contribution to the hazard at LLNL because it approaches to within $1 \mathrm{~km}$ of the site. Characterization of this fault follows the two-segment model adopted by WG99, but its geometry and slip rate distributions are defined in considerably more detail than is required in that study. Definition of the source geometry is based on recent detailed geomorphic and structural mapping of the fault by Unruh and Sawyer (1998), which built upon earlier investigations (e.g., Herd, 1977; Dibblee, 1980a; Hart, 1981; Sweeney and Springer, 1981). The fault segments are shown in Figure 5, and segment parameters are given in Table 2. WG99 defines the boundary between the north and south Greenville Fault segments at the fault's intersection with the Las Positas Fault, based upon the change in the general character and structural setting of the Greenville Fault in this vicinity (T. Sawyer, written communication, Feb. 10, 2000). However, the location of this boundary is subject to large uncertainty, which, because of its proximity to the site, translates to significant hazard uncertainty. 
Table 2. Local earthquake source parameters.

\begin{tabular}{llcllll}
\hline \multicolumn{2}{c}{ Fault segment } & \multicolumn{1}{c}{$\mathbf{L}$} & \multicolumn{1}{c}{$\begin{array}{c}\mathbf{D}_{\mathbf{1}} \\
\mathbf{( k m})\end{array}$} & $\begin{array}{c}\mathbf{D}_{2} \\
\mathbf{( k m})\end{array}$ & $\begin{array}{c}\text { Dip } \\
\mathbf{( d e g})\end{array}$ & $\begin{array}{c}\mathbf{V} \\
\mathbf{( m m} / \mathbf{y r})\end{array}$ \\
\hline Greenville: & North & $23 \pm 12$ & $0+2 / 0$ & $18 \pm 3$ & $90+15 /-10$ & $2.0+2.5 /-1.8$ \\
& South & $24 \pm 12$ & $0+2 / 0$ & $15 \pm 3$ & $90+15 /-10$ & $2.0+2.5 /-1.8$ \\
Las Positas & & $16+2 /-3$ & $0+2 / 0$ & $15 \pm 3$ & $90 \pm 10$ & $0.6+1.0 /-0.5$ \\
Mt. Diablo Th.: NW & $10 \pm 5$ & $3.5+1.5 /-3.5$ & $18 \pm 3$ & $45+5 /-25$ & $2.5 \pm 1.5$ \\
& Cent. & $11 \pm 5$ & $4 \pm 2$ & $18 \pm 3$ & $30+20 /-10$ & $2.5 \pm 1.5$ \\
& SE & $10 \pm 5$ & $4 \pm 2$ & $10+6 /-2.5$ & $30+20 /-10$ & $2.5 \pm 1.5$ \\
Verona & & $5+3 /-2$ & $0+2 / 0$ & $160 /-6$ & $45+25 /-15$ & $0.7+0.7 /-0.6$ \\
Williams & & $11+3 /-4$ & $0+2 / 0$ & $14+4 /-5$ & $45+25 /-15$ & $0.2+1.1 /-0.2$ \\
Corral Hollow & & $9 \pm 5$ & $0+2 / 0$ & $17+4 /-3$ & $90 \pm 20$ & $0.7+1.3 /-0.65$ \\
Carnegie & & $8+7 /-5$ & $0+2 / 0$ & $17+4 /-3$ & $90 \pm 20$ & $0.7+1.3 /-0.65$ \\
Livermore & & $8+1 /-2$ & $1+2 /-1$ & $13+2 /-6$ & $65+10 /-20$ & $1.0+0.5 /-0.9$ \\
Springtown & & $4+3 /-2$ & $0+2 / 0$ & $8 \pm 3$ & $70+5 /-10$ & $1.0+0.5 /-0.9$ \\
Mt. Lewis & & $13 \pm 3$ & $0+2 / 0$ & $12+3 /-5$ & $90 \pm 10$ & $1.0+1.0 /-0.9$ \\
Ortigalita: & \multirow{2}{*}{ North } & $40+15 /-5$ & $0+2 / 0$ & $14 \pm 2$ & $90 \pm 10$ & $1.5+0.6 /-1.0$ \\
& South & $38+22 /-24$ & $0+2 / 0$ & $14 \pm 2$ & $90 \pm 10$ & $0.5+0.5 /-0.4$ \\
\hline
\end{tabular}

Data presently available to constrain the Greenville slip rate are sparse. Earlier estimates (e.g., Sweeney, 1982; Wright et al., 1982) are in the range $0.2-0.7 \mathrm{~mm} / \mathrm{yr}$. This is based upon observations that yield slip rate estimates averaged over widely varying time intervals ranging from tens of millions to 100-200 thousand years. However, the well-defined morphology of the fault zone is consistent with a Quaternary slip rate of $1 \mathrm{~mm} / \mathrm{yr}$ or greater (Unruh and Sawyer, 1998). This has yet to be verified by data. Sawyer and Unruh (2000) found evidence for one Holocene earthquake in three trenches on Crane Ridge, southeast of LLNL, but were unable to estimate a definitive slip rate. If, as assumed by Sawyer and Unruh, this is the most recent event and using their coseismic slip estimate of $1.25 \pm 0.25 \mathrm{~m}$, then carbon-14 dating of bulk samples suggests a maximum slip rate in the range $0.25-0.5 \mathrm{~mm} / \mathrm{yr}$. This is very tentative, however. Sawyer and Unruh opened four new trenches across the fault at Laughlin Road., north of LLNL, in 2001, where their working hypothesis of a stream channel offset across the fault suggests a slip rate of $1-2 \mathrm{~mm} / \mathrm{yr}$ or greater. Age dating of samples from these trenches is currently being carried out at the LLNL Center for Accelerator Mass Spectroscopy. An alternative way of estimating the Greenville slip rate is by inferring it from the transpressional kinematic model proposed by Unruh and Sawyer (1997) and Unruh (2000). In this model, slip is transferred from the Greenville to the Concord-Green Valley fault via the blind Mt. Diablo thrust (see Figure 5, and below), so that estimates of the slip rates on the Concord Fault and Mt. Diablo thrust can be 
used to infer the slip rate on the Greenville fault. This yields an estimate in the range 1 to 4 $\mathrm{mm} / \mathrm{yr}$.

Mt. Diablo Thrust: Unruh and Sawyer (1997) propose that the Mt. Diablo blind thrust underlying the Livermore and Sycamore valleys is the source of the major fold structures in the area, including Mt. Diablo and the Mt Diablo and Tassajara anticlines. Unruh and Sawyer modeled these anticlinal structures as fault-propagation folds over the blind tip of the proposed Mt. Diablo thrust. The folds, and hence the underlying fault, are assumed to be active because they deform late Pleistocene and early Holocene sediments (Unruh and Sawyer, 1997; Unruh, 2000). The geometry and slip rate on the thrust are inferred largely from structural modeling, although the existence of the thrust is consistent with seismic reflection data from the southeastern Tassajara Hills (Unruh, 2000). This blind thrust is the only fault included in the WG99 characterization that is not part of the right-lateral San Andreas system, and is a significant new local source for the LLNL PSHA.

The Mt. Diablo thrust is identified by Unruh and Sawyer as part of what they term the Mt. Diablo fold and thrust belt, which includes the surface Williams and Verona faults southwest of the Livermore Valley, and the Livermore and Springtown structures in the immediate vicinity of the LLNL site (see Figure 5 and below). Unruh and Sawyer hypothesize that this system has formed in a left-stepping transpressional step-over between the right lateral Greenville and Concord-Green Valley faults, and propose a kinematic model in which slip on the Greenville fault is transferred via the Mt. Diablo thrust to the Concord Fault. Present modeling results constrain estimates only of the minimum slip rate on the Mt. Diablo thrust averaged over several million years, which depend upon the timing of initiation of folding. The maximum age of initiation is estimated to be between 6.2 Ma and 3.3 Ma, which yields a minimum slip rate in the range 1.3 to $2.4 \mathrm{~mm} / \mathrm{yr}$ (Unruh, 2000). According to the Unruh and Sawyer transpressional model, this range is generally consistent with the $4 \pm 2 \mathrm{~mm} / \mathrm{yr}$ slip rate estimate for the Concord Fault assigned by WG99. At present, there is no evidence to constrain the minimum age of the onset of folding; if this occurred later than $3.3 \mathrm{Ma}$, then the average slip rate would be greater than $2.4 \mathrm{~mm} / \mathrm{yr}$.

Las Positas Fault: Based on its estimated area and slip rate, the Las Positas Fault appears capable of generating relatively infrequent moderate earthquakes. However, it makes a substantial contribution to the hazard because it passes within $1 \mathrm{~km}$ of the LLNL site. Characterization of the Las Positas Fault is based largely on the original mapping of Herd (1977), fault evaluation reports by the California Division of Mines and Geology (CDMG; T.C. Smith, 1981; Hart, 1981), and particularly on the extensive field geological and geophysical investigations and analyses by LLNL Geosciences (Carpenter and Clark, 1982; Carpenter et al., 1984). There is moderately strong evidence for latest Pleistocene-Holocene activity, and equivocal evidence that the fault may have experienced historical events (Carpenter et al., 1984; Hart, 1981). However, despite the detailed field investigations carried out by LLNL, the fault 
remains poorly understood and its slip rate uncertain although apparently low (in the range $\sim 0.1$ to $\sim 1 \mathrm{~mm} /$ year).

Characterization of the Las Positas Fault requires consideration of its structural and kinematic relationships to the Greenville, Verona, and Williams faults and to the hypothesized Livermore and Springtown blind reverse faults (see below). However, these relationships are largely a matter of conjecture, since the sub-surface geometries of all of the faults except the Greenville are unconstrained. One interpretation (T. Sawyer, personal communication, 2001) is that the assumed sub-vertical, left-lateral Las Positas Fault acts as a tear fault separating the thrust/reverse Williams and Verona faults, in which case the slip rates on the individual faults have to be kinematically balanced. Alternatively, the Verona and Williams faults may be continuous below some depth, in which case the Las Positas Fault is a hanging wall structure, antithetical to the Greenville Fault, and its slip rate is not directly coupled to the underlying thrust. Each of these alternatives forms a separate branch in the logic tree input to the hazard calculations.

Verona and Williams faults: The Verona Fault was the subject of considerable debate in the late 1970s, yet it remains very poorly understood (e.g., Rice et al., 1979). There is still insufficient information to be able to definitely identify the structure as tectonic (Herd and Brabb, 1980), rather than a massive landslide feature. CDMG designated the northernmost $5.65 \mathrm{~km}$ of the feature as mapped by Herd (1977) as an active fault according to the State of California Alquist-Priolo Act. The favored interpretation (Herd and Brabb, 1980) is that the fault dips gently northeast, although the sub-surface geometry is unconstrained. Splays of the fault displace Holocene material. The only slip rate estimate for the Verona Fault is $0.12 \mathrm{~mm} / \mathrm{yr}$ (Jahns and Harding, 1982), but this is highly uncertain. The trace geometry shown in Figure 5 is based on the original Herd (1977) map.

The Williams Fault is even more poorly understood. There is no definitive evidence for Holocene activity, although the fault cuts Quaternary sediments. The appearance (e.g., Dibblee, 1980b) that the Williams trace continues the trend of the Verona Fault suggests one plausible model is that the Verona and Williams traces are the surface expressions of a single fault at depth. If this fault dips gently northeast, as suggested by near-surface splays of the Verona Fault, then this thrust could be a component of the Mt. Diablo fold and thrust belt of Unruh and Sawyer (1998) and Unruh (2000). On a more local scale, T. Sawyer (personal communication, 2001) hypothesizes that the Verona, Williams, Las Positas, Livermore, and Springtown faults are components of a "Verona thrust system." As described earlier, the Las Positas Fault would be either a hanging wall or tear fault within this system, depending on whether the slip rates of the Verona and Williams faults are assumed to be equal or not. Another alternative is that the Williams fault (and/or the Verona fault) is inactive; note that D.P. Smith (1981, reported in Carpenter et al., 1984) interpreted the trace geometry and geomorphology of the Williams Fault to suggest a southwest dip and right-normal displacement. Slip rates on the Verona-Williams 
system are estimated indirectly from the sparse data available for the Las Positas Fault and the Springtown blind fault (see below) according to the different structural/kinematic interpretations of the Verona fold and thrust system.

Livermore and Springtown faults: The existence and activity of the Livermore Fault have been the subjects of some debate since the fault was proposed by the California Department of Water Resources (CDWR, 1966, 1974; reported in Carpenter et al., 1984), based primarily on a groundwater barrier and an apparent outcrop in Plio-Pleistocene sediments at Oak Knoll in Livermore. CDWR (1979; reported in Carpenter et al., 1984) also proposed that the fault extends to the southeast to Del Valle reservoir, based on observed shears within Plio-Pleistocene sediments (but not overlying colluvium). However, this interpretation is in conflict with the more compelling evidence for the activity of the Las Positas Fault, since the postulated Livermore Fault would cut across the Las Positas without offset. CDMG does not consider the fault active for Alquist-Priolo zoning. An alternative possibility is that the Livermore Fault exists only north of the Las Positas Fault. To our knowledge, no estimates of either the sense of slip or slip rate have been attached to the fault as postulated by CDWR, although right-lateral displacement is suggested based on the strike, which is sub-parallel to the Greenville Fault.

An entirely different interpretation was proposed by Sawyer (1998) in the context of the Mt. Diablo fold and thrust belt. The Livermore trend is characterized by uplifted alluvial surfaces cut by wind gaps that Sawyer interprets as ancestral courses of Arroyo Mocho. The elevations of the wind gaps decrease progressively from southeast to northwest. A plausible explanation of these observations is that the Livermore trend is an active anticline that is growing laterally and deflecting Arroyo Mocho to the northwest. The anticline is truncated (or offset) on the southeast by the Las Positas Fault. Like the large-scale active folds, Sawyer proposes that the anticline is a fault propagation fold above the blind tip of an active northeast-dipping reverse fault. Similarly, the active Springtown anticline (Unruh and Sawyer, 1997; Sawyer, 1998) is interpreted as a fault propagation fold above a blind southwest-dipping backthrust off the Livermore Fault. These anticlines/faults are relatively short and are considered to be secondary structures within the fold and thrust belt. Like the Verona/Williams Fault, the subsurface geometries of the postulated Livermore and Springtown faults are unconstrained; depending on the dip of each of the faults, the Livermore Fault could root into the Verona/Williams Fault, extend to the base of the seismogenic crust, or splay off the Greenville Fault.

A single carbon-14 date yields a maximum estimate of the Holocene uplift rate on the Springtown anticline of 0.7 to $0.9 \mathrm{~mm} / \mathrm{yr}$ (Unruh and Sawyer, 1997), suggesting a maximum dip slip rate of about $1 \mathrm{~mm} / \mathrm{yr}$. The average late Quaternary slip rate is estimated as 0.1 to 0.25 $\mathrm{mm} / \mathrm{yr}$. This long-term average is consistent with a tentative uplift and slip rate estimate on the order of $0.1 \mathrm{~mm} / \mathrm{yr}$ for the Livermore Fault, based on the stream incision rate for Arroyo Mocho (Sawyer, 1998). 
Corral Hollow and Carnegie faults: The Corral Hollow-Carnegie fault zone as mapped by Dibblee (1980c) and Crane (1995) passes about $3 \mathrm{~km}$ east of LLNL at its closest approach. Carpenter et al. (1991) found evidence for repeated movement during the Pleistocene and Holocene on a fault strand within Site 300, between the mapped traces of the Corral Hollow and Carnegie faults, and suggested that the fault zone as a whole should be considered potentially active. Dibblee (1980) mapped the Corral Hollow Fault as a right-lateral fault sub-parallel to and east of the Greenville Fault, and shows it offsetting the Corral Hollow syncline in a right-lateral sense. Age control on slip rates by Carpenter et al. (1991) was based on soil stratigraphy, so estimates have large uncertainties. Schlemon (Appendix B in Carpenter et al. [1991]) speculates that an earthquake may have ruptured the fault zone during the past few hundred years, which would imply a slip rate of 1 to $2 \mathrm{~mm} / \mathrm{yr}$, comparable to that of the Greenville Fault. Longer-term average estimates over the last $60-70 \mathrm{ka}$, however, are very low, in the range $0.05-0.07 \mathrm{~mm} / \mathrm{yr}$.

Mt. Lewis Fault: Characterization of the Mt. Lewis Fault is based on the March 31, 1986, $\mathrm{M}_{\mathrm{L}} 5.7$ earthquake and its immediate aftershock distribution (Zhou et al., 1993), which sharply delineates a 16-km-long north-south trend, consistent with the right-lateral focal mechanism of the mainshock. The background microseismicity suggests that the fault may extend as far north as the Williams Fault. A cross-section through the seismicity clearly defines a sub-vertical plane to a depth of about $10 \mathrm{~km}$. The fault had not been recognized before the 1986 event, although it corresponds to a lineament on Landsat images (D. Schwartz, personal communication, 2000). There are no direct observations to constrain the slip rate on this fault. Kinematic modeling of geodetic data suggests a slip rate on the order of $1 \mathrm{~mm} / \mathrm{yr}$. 


\section{Ground Motion Attenuation Models}

\subsection{Ground Motion Modeling and Uncertainty}

The choice of ground motion attenuation models for use in PSHA should reflect our best understanding of the local geology and regional wave propagation properties and the characterization of the earthquake sources. Ideally, a combination of physical models and observed strong motion data would produce the necessary models. Rarely is there a sufficient number of ground-motion recordings near a site to allow a direct empirical estimation of the motions expected for a particular set of conditions (magnitude, distance, fault geometry, source parameters). It is therefore necessary to develop relationships, expressed in the form of equations or look-up tables, for estimating ground motions in terms of magnitude, distance, site conditions, and other variables from the body of strong-motion data from a large region or a particular tectonic setting.

There has been a large number of earthquakes in the last decade that produced strong motion data. In addition, new modeling techniques have also led to a variety of new functional forms, some based on principles of seismology (e.g., Joyner and Boore, 1982), and others based more on statistical considerations (e.g., Campbell, 1997). Some models are also based largely on ensembles of numerically simulated data.

Recently, the Chi-Chi earthquake, in Taiwan (1999), and the Izmit, Turkey, earthquake (1999) provided a wealth of new data in the near field and for relatively large magnitudes. This led to a general updating of a number of existing models. It also provided the opportunity to introduce new independent parameters such as the source mechanism, directivity, and basin effects.

This has enabled modeling of the aleatory uncertainty to be refined. The standard error "sigma" that expresses the aleatory uncertainty in an attenuation model can now be expressed in terms of magnitude, distance from the site, and/or ground motion (acceleration) level.

The epistemic uncertainty, stemming from the differences in formulation of models by individual experts in the last decade, has not changed substantially, however.

In this study, we considered the latest published models and used the correction factors that are provided for different styles of faulting (strike-slip, normal, or reverse), and the relative position of the site with respect to the fault (foot-wall, hanging-wall). The estimates of the seismic hazard are based on the average of the two horizontal components of the ground motion, for a free-field instrument at a hypothetical California rock site (shear wave velocity $\mathrm{V}_{\mathrm{s}}$ around $600 \mathrm{~m} / \mathrm{sec}$ ) and for a generic western soil site $\left(\mathrm{V}_{\mathrm{s}}\right.$ around $\left.310 \mathrm{~m} / \mathrm{sec}\right)$. 
The epistemic uncertainty in the ground motion modeling was quantified by sampling through the community of ground motion models experts. We used a set of models from a selected group of experts who represent the knowledge of the scientific community for the region, and we assigned weights to each of them, according to the degree to which we believed they explained the data.

For each model selected, we used the characterization of the aleatory uncertainty "sigma," as stipulated by the developer of the model, who presumably would have fitted that uncertainty to the data.

\subsection{Selected Attenuation Models}

For both the peak ground acceleration and for the spectral values, we selected a set of four models, whose general form is described in Seismological Research Letters 1997, with updates from the Taiwan and Turkey data (Abrahamson, 2000). These models are the following:

1. Abrahamson and Silva (1997)

2. Boore, Joyner and Fumal (1997)

3. Campbell (1997)

4. Sadigh, Chang, Egan, Makdisi, and Youngs (1997)

For each of the models, spectra are defined at nine frequencies: 33.3, 20.0, 10.0, 6.67, 5.0, 3.33, 2.0, 1.0, and $0.5 \mathrm{~Hz}$. For those models that did not provide all these frequencies, we interpolated between the closest frequency values. 


\section{Results of Rev. 2 Analysis}

\subsection{Hazards Results}

The results are presented in the form of hazard curves, for the 15th, 50th (median), and 85th percentile and mean estimates of the average of the two horizontal components of the ground motion. The corresponding curves for PGA are shown in Figure 6 for the rock case and Figure 7 for the generic soil case. Mean Uniform Hazards Spectra (UHS) are constructed as loci of spectral values with the same probability of exceedance at each of the nine frequencies. Figure 8 shows the mean UHS for rock and Figure 9 for generic soil, in terms of pseudo-absolute accelerations. Figures 8 and 9 are 5\% damping and for five return periods: 100, 500, 1000, 2000, and 10000 years, where the return period is defined as the inverse of the probability of exceedance.

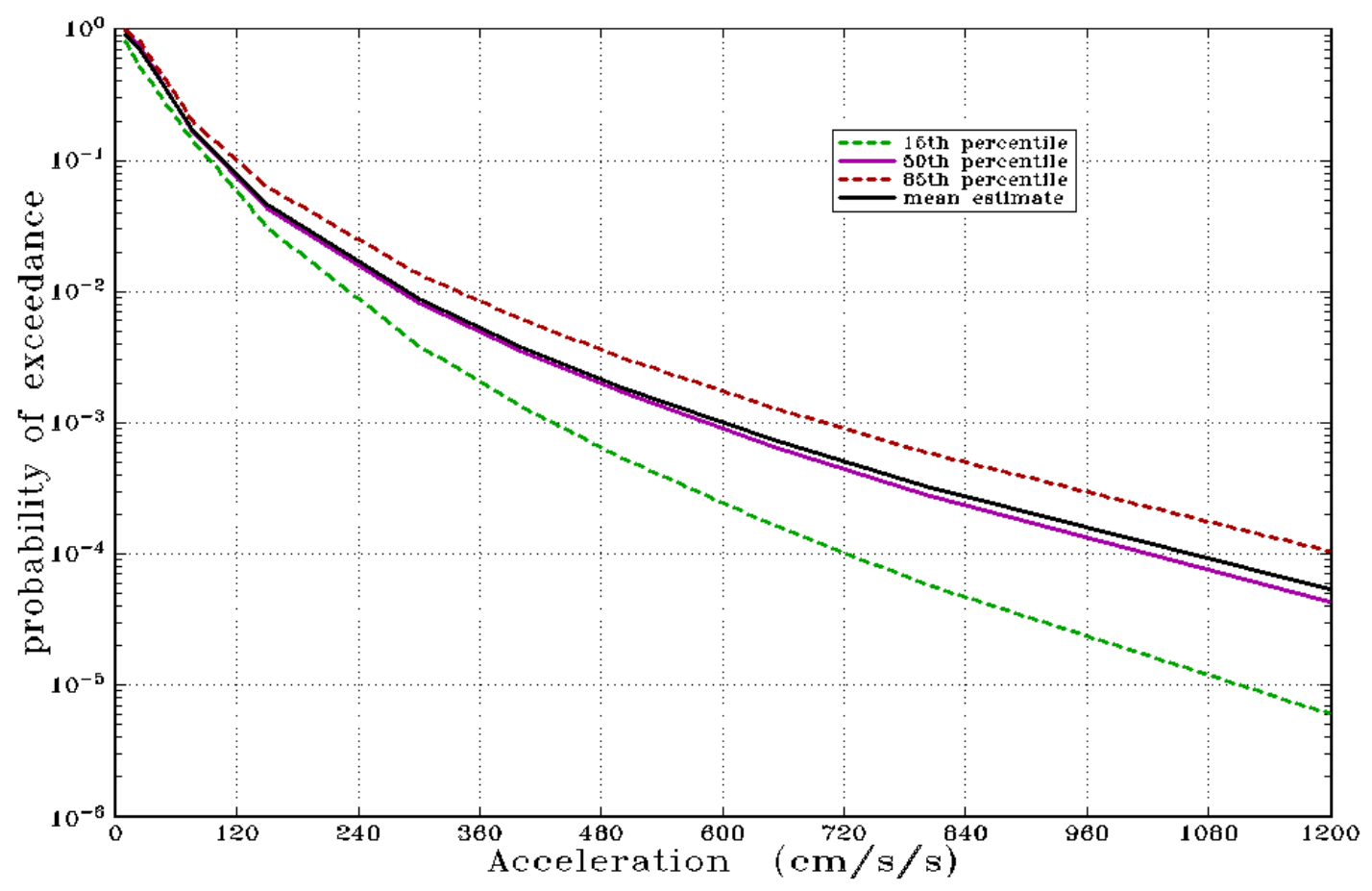

Figure 6. California rock PGA-PSHA results for the LLNL site. 


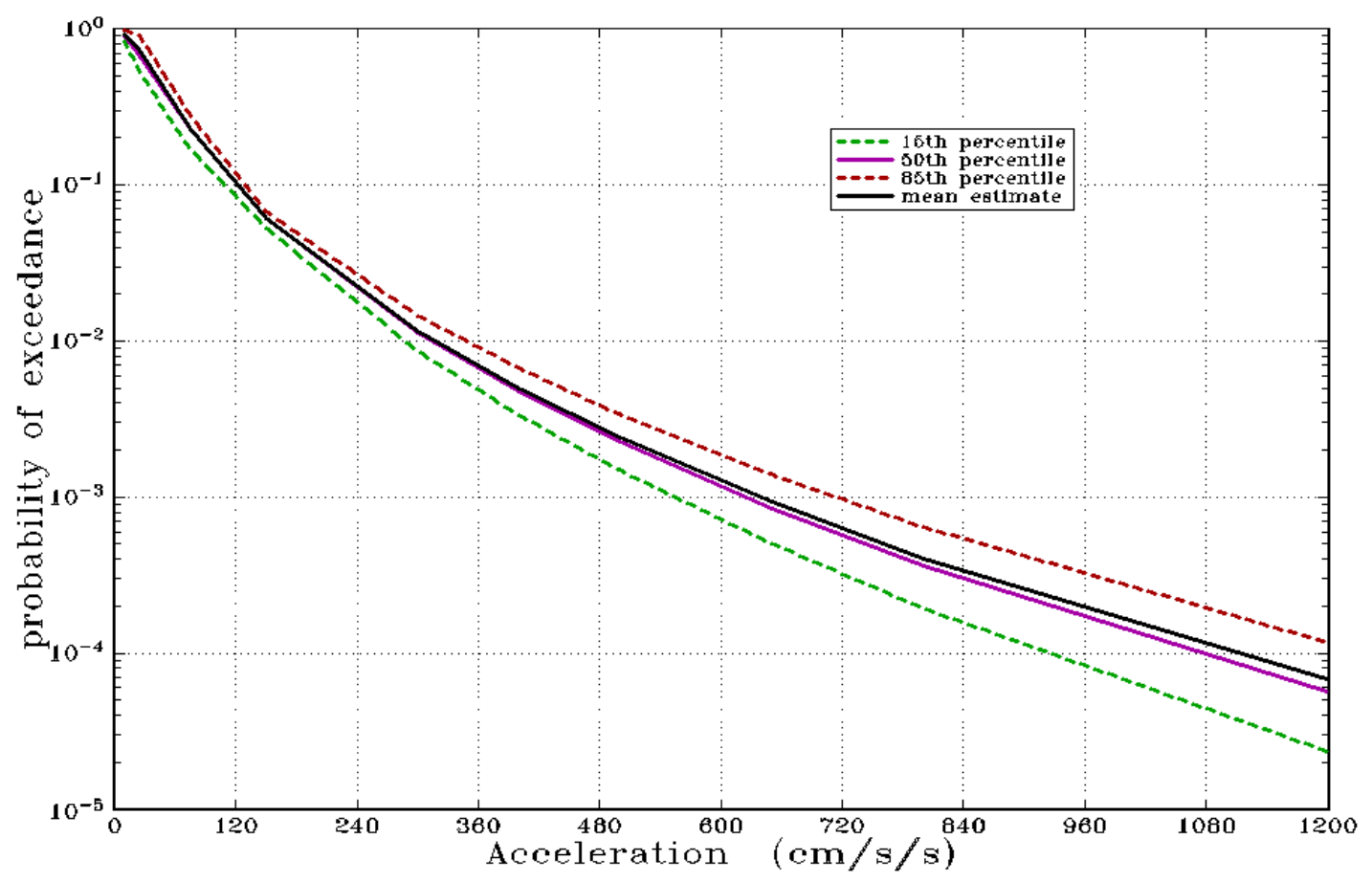

Figure 7. Generic soil PGA-PSHA results for the LLNL site.

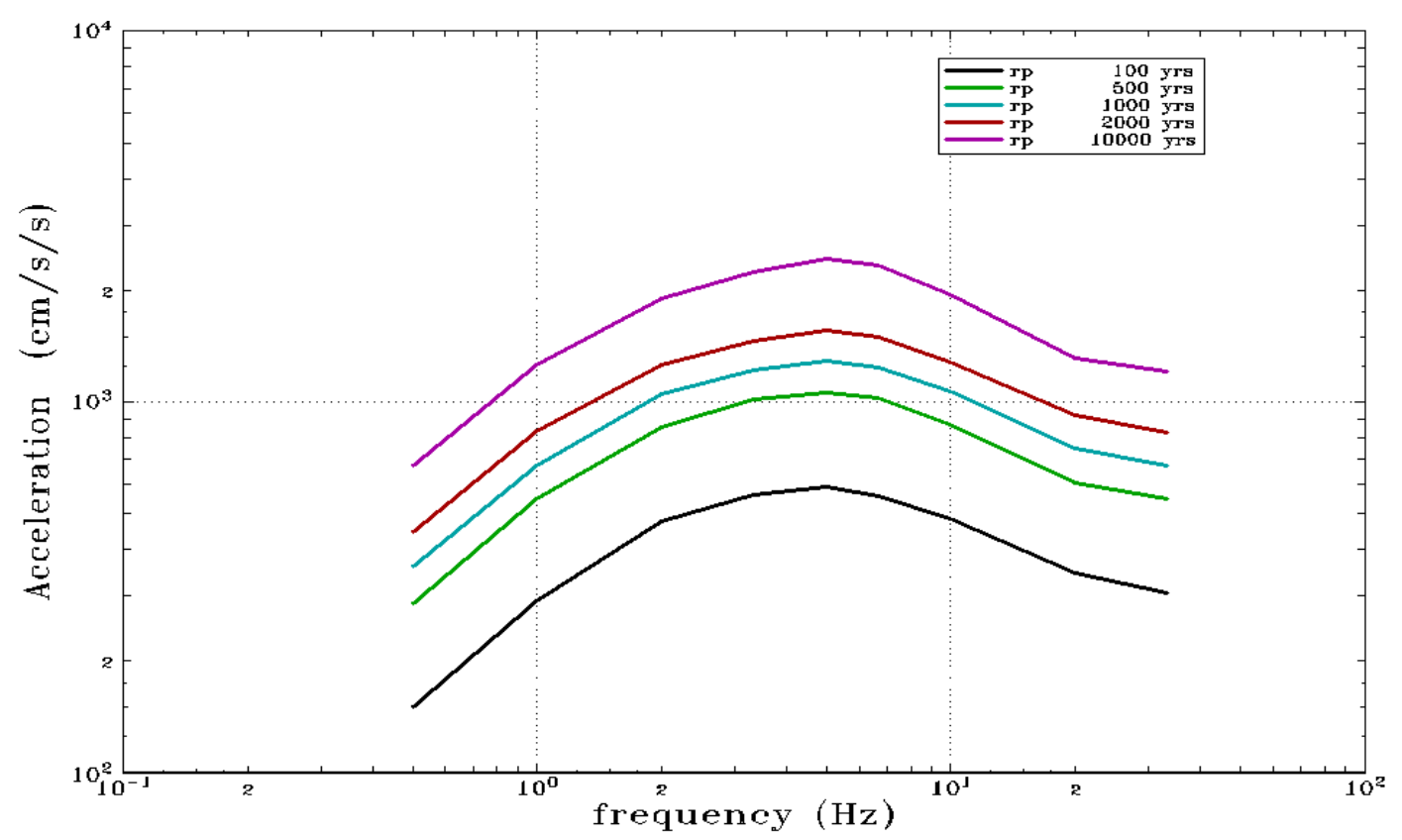

Figure 8. Mean uniform hazard spectra for rock at the LLNL site (5\% damping). 


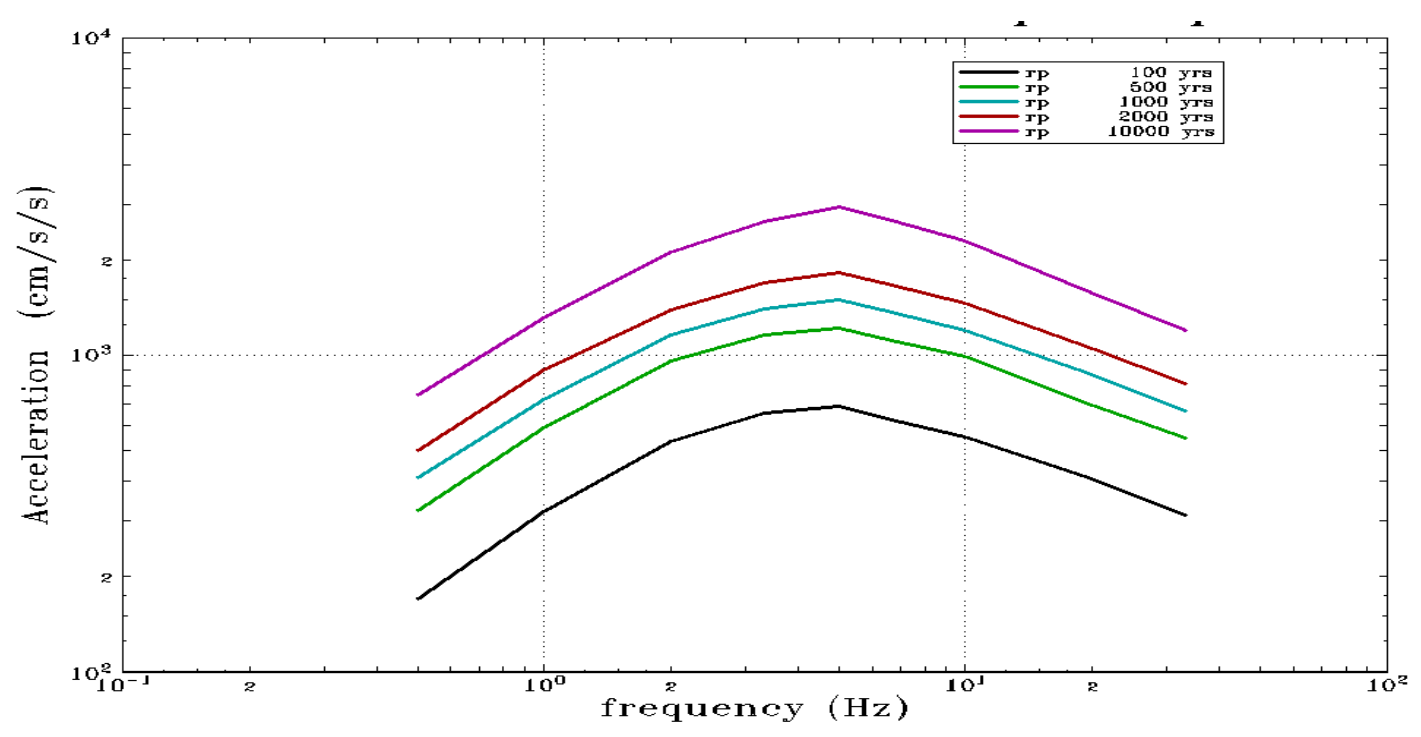

Figure 9. Mean uniform hazard spectra for generic soil at the LLNL site ( $5 \%$ damping).

\subsection{De-aggregation Results}

The hazard results were de-aggregated to show the relative contribution to the total hazard from each individual seismic source, and from each discreet small range of magnitude and distance values (referred to as M-D "bins"). This latter operation is necessary to calculate the M-bar and D-bar values as required by DOE standard DOE-STD-1020. M-bar and D-bar are used to define the shape of the deterministic response spectrum that should be used as a design parameter.

There is no unique way for expressing quantitatively the relative contribution of each of the seismic sources, and to this date, there is no consensus in the community of PSHA practitioners to achieve that purpose. In this study, we calculate the hazard generated by each seismic source (or fault system) separately, and calculate the ratio of that to the total hazard, where all the sources contribute. This contribution, which is displayed in Figure 10 in terms of a percentage, can be calculated for any representative statistic of the distribution of the hazard. Sensitivity analyses have shown us that in general the median hazard estimates lead to more stable and realistic representations of the relative importance of each of the seismic sources, and consequently Figure 10 shows the relative contribution of the main faults, to the total median hazard, in the rock case. 


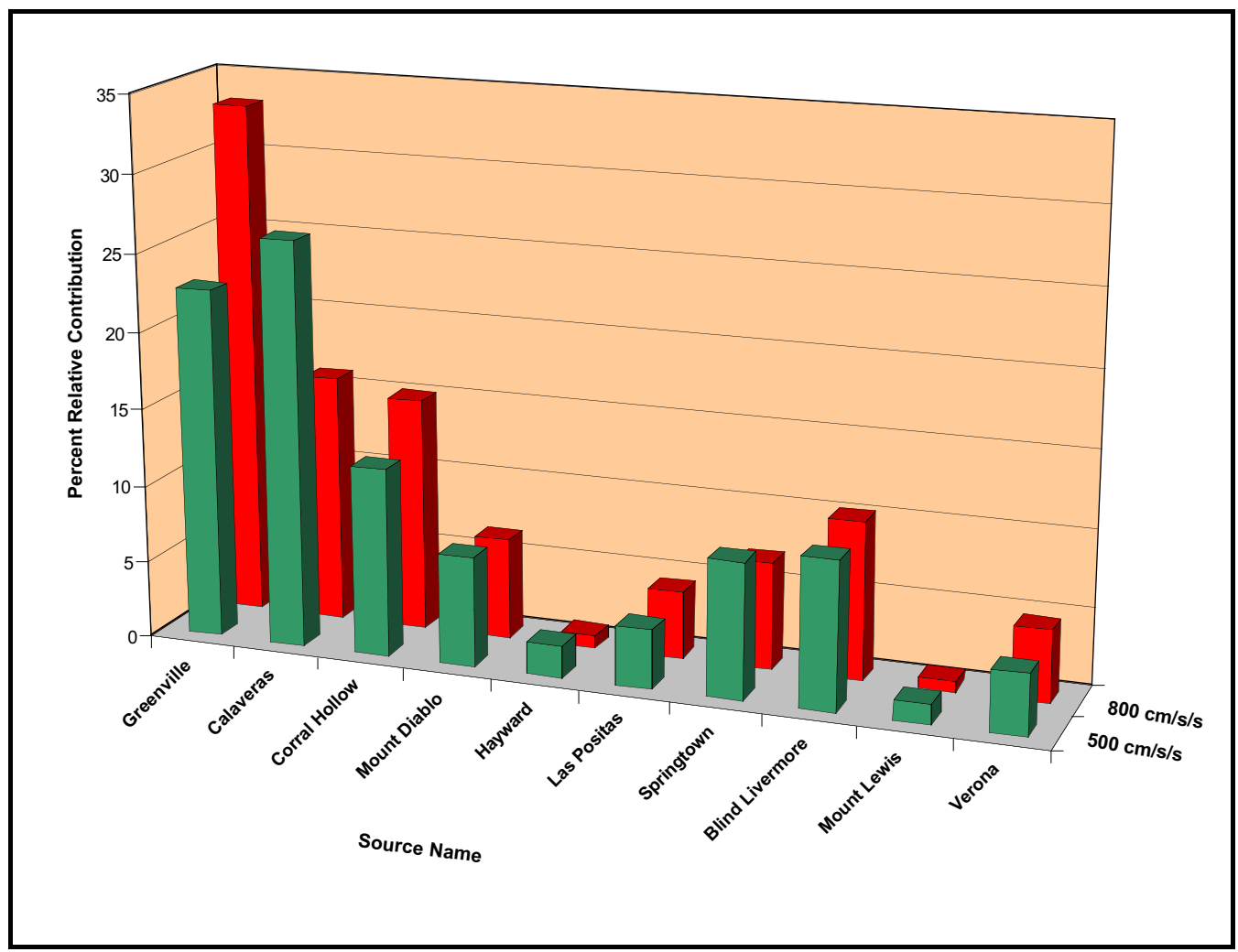

Figure 10. Relative contribution of the individual sources to the total PGA-median PSHA for 500 $\mathrm{cm} / \mathrm{s} / \mathrm{s}$ and $800 \mathrm{~cm} / \mathrm{s} / \mathrm{s}$, or approximately 500 -year and 2000-year return periods.

Figure 11 shows the relative contribution to the 2000-year return period PGA in the case of rock. The main contribution to the hazard comes from sources within 5 to $25 \mathrm{~km}$, and for magnitudes between magnitudes 6 and 7. Accordingly, Figure 10 shows the Greenville, Corral Hollow, and Calaveras faults to dominate.

Similar results are obtained for the generic-soil case, and for each of the nine frequencies, and for each of the five return periods of the analysis. Some of the more distant sources make larger contributions at the shorter return periods. This is also true for lower frequencies $(0.5 \mathrm{~Hz}$ and $1.0 \mathrm{~Hz}$ ), as shown in Figure 12 for $1 \mathrm{~Hz}$. This figure shows that for the low frequencies, a source, probably the Hayward and/or San Andreas fault, located at a distance of approximately 50 to 70 $\mathrm{km}$, contributes substantially to the hazard. 


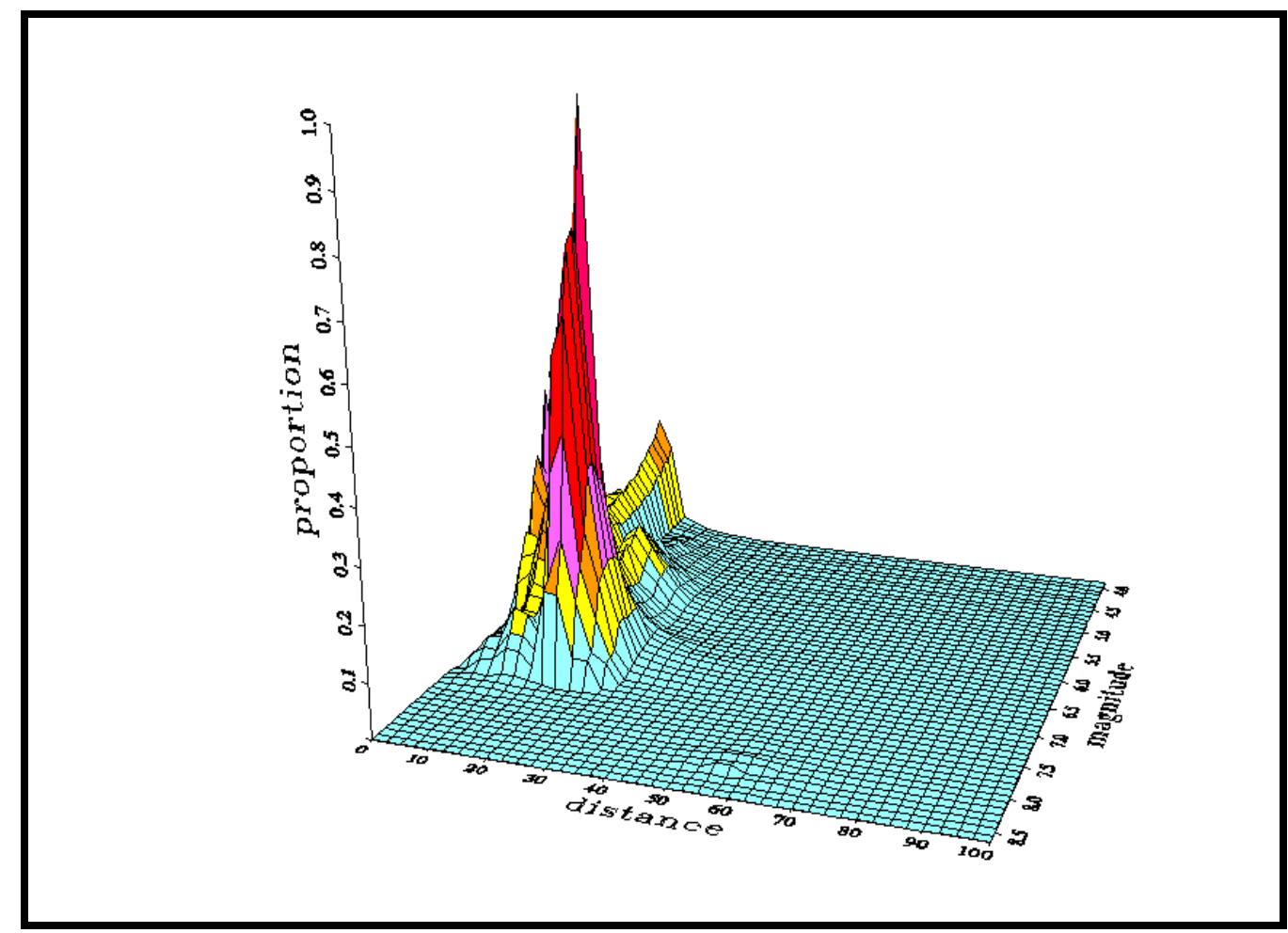

Figure 11. M-D bin contributions to the 2000-year return period PGA-PSHA.

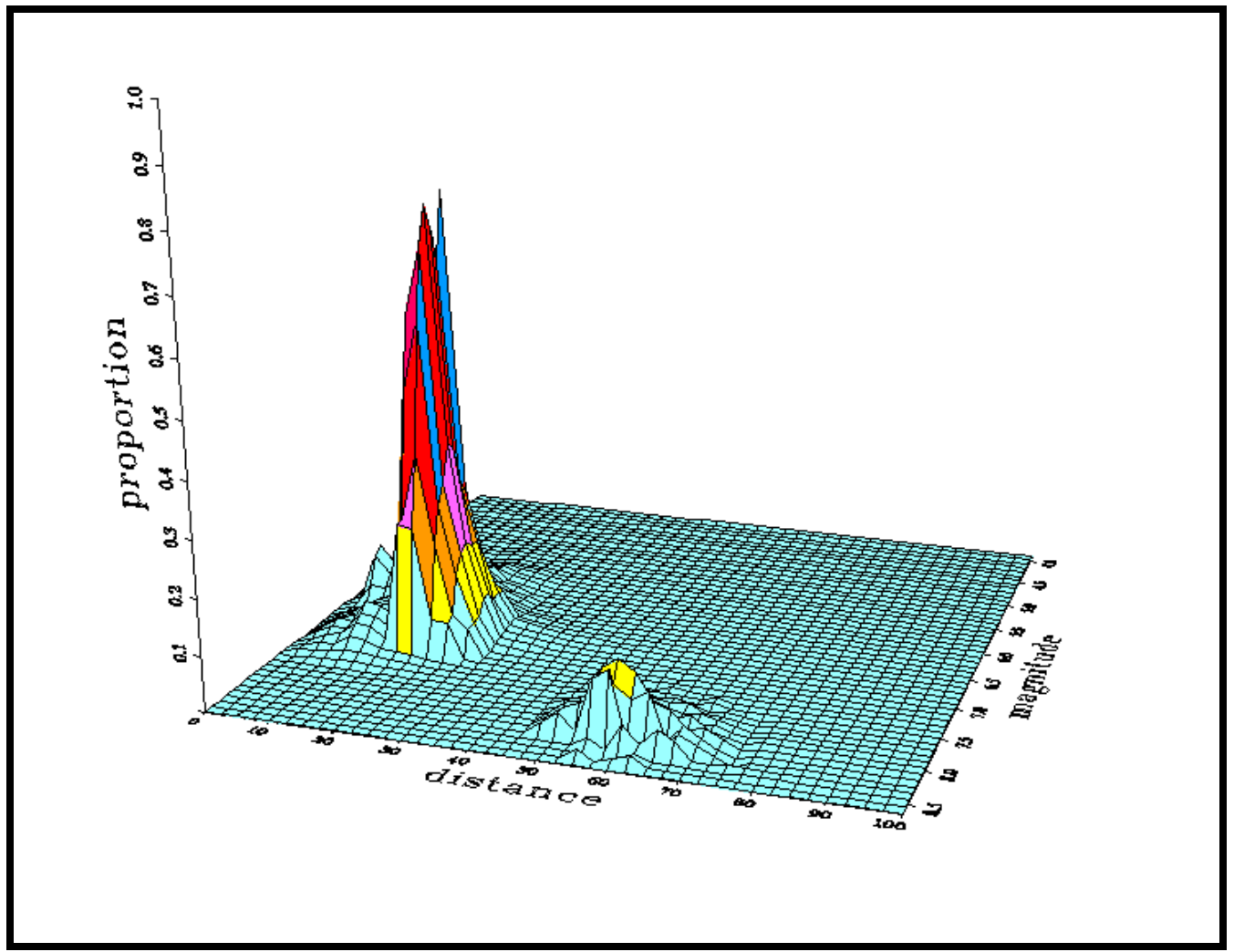

Figure 12. M-D bin contributions to the 2000 -year return period for $1 \mathrm{~Hz}$. 


\section{Comparison with Previous Results; Discussion}

Figure 13 reproduces the results from the Rev 1, 1991, results, superimposed with the results from this study for the rock case, and Figure 14 shows the same for the generic soil case.

Figure 14 shows that the mean hazard estimates in the generic soil case are essentially identical for the two studies. However, it must be noted that the uncertainty estimates are different.

The 5th and 95th percentiles provided in the Rev. 1, 1991, study define a larger band of uncertainty than the 5th to 95th percentiles in the Rev 2 study; the 95th percentiles are approximately equal. Therefore this study narrowed down the estimates of the uncertainties by eliminating the alternatives that would lead to very low estimates of the seismic hazard. Our estimates of the uncertainties in the dispersion of the ground motion from the predictions with the attenuation models (the "sigma" values) are smaller than in the previous studies. The same is true for some of the occurrence models. We have included a more realistic representation of the uncertainties in the geometry of the dominant faults, as well as a number of conceptually different alternatives for the general tectonics of the region. The addition of the Mount Diablo thrust as a series of three possibly disjoint segments also contributed to raising the hazard as well as increasing the overall uncertainty.

In the end, these effects have worked in opposition to finally provide a set of estimates of the mean hazard that is close to the results of the 1991 study, in spite of the different approach to the treatment of the uncertainties, the different set of alternative tectonic models, and the large quantity of new information that was generated in the last decade. This new study provides more insights into the identification of the dominant seismic sources, and it determines the ground motion in terms of uniform hazard response spectra. 


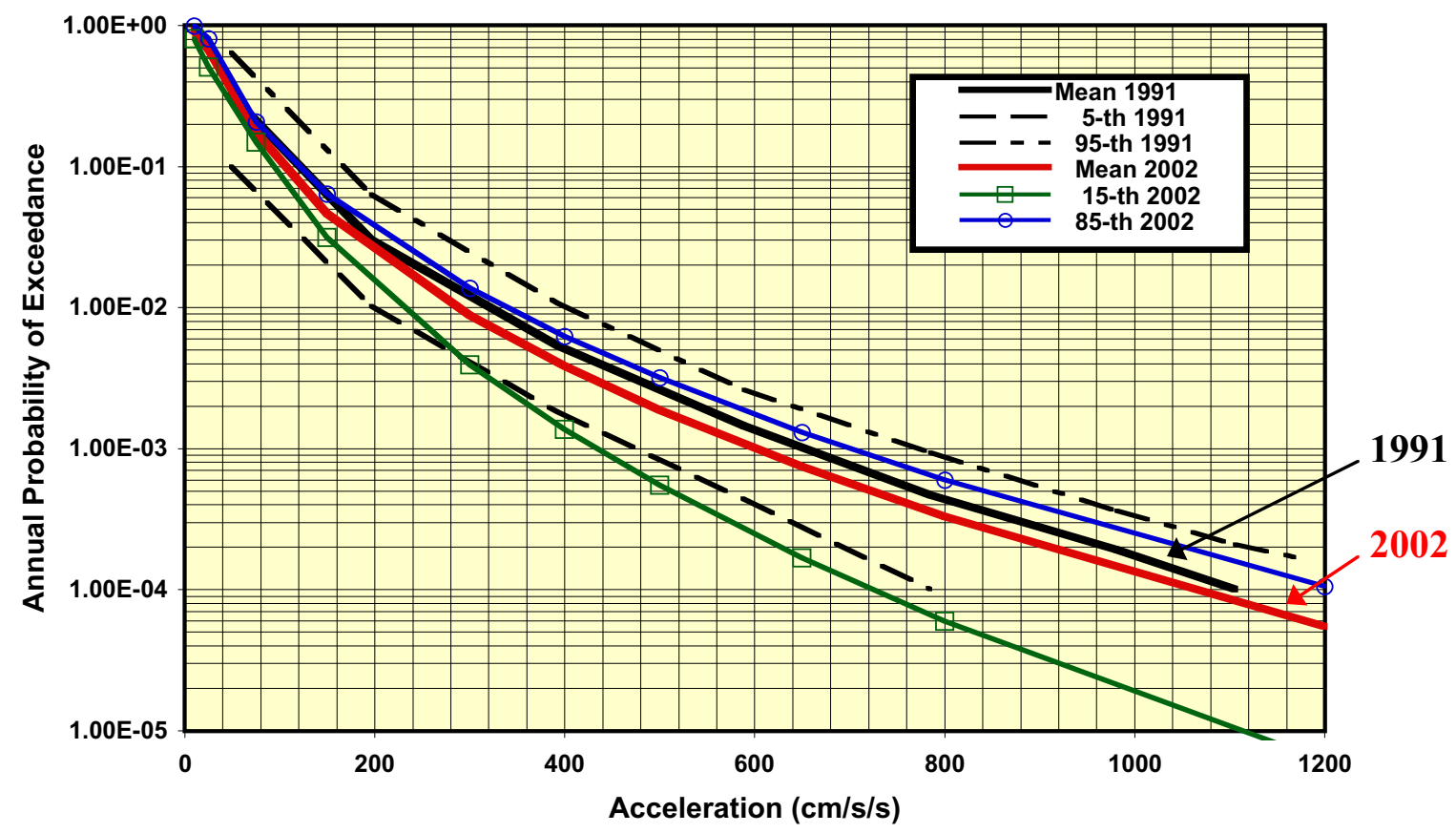

Figure 13. Comparison of Rev. 1 results with Rev. 2 results for rock.

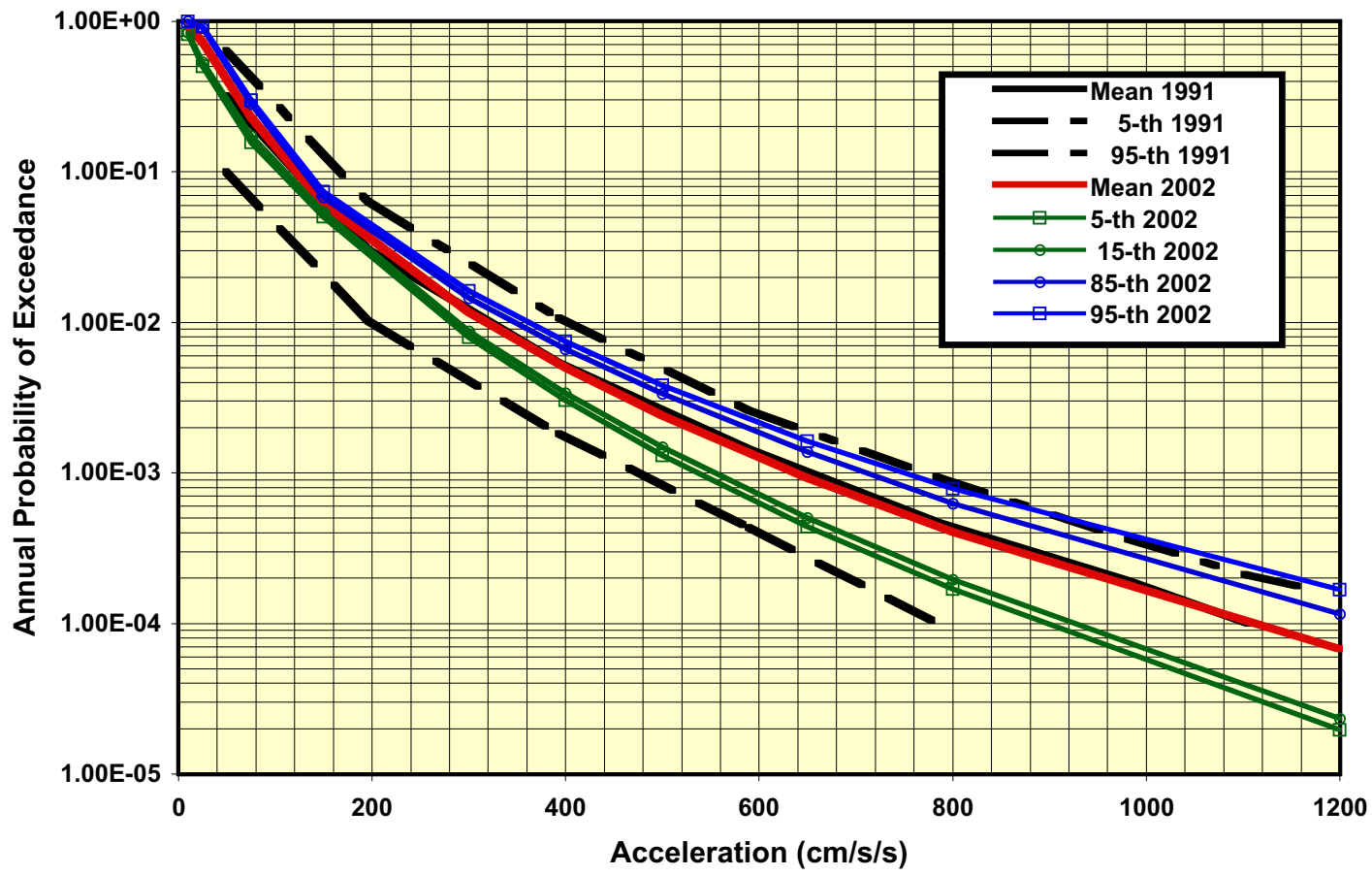

Figure 14. Comparison of Rev. 1 results with Rev. 2 results for soil. 


\section{References}

Abrahamson, N.A. (2000), consultant, personal communication.

Abrahamson, N.A. and W.J. Silva (1997), Empirical Response Spectral Accelerations for Shallow Crustal Earthquakes, Seism. Res. Let. 68, No. 1, 94-127.

Bakun, W.H. (1999), Seismicity Activity of the San Francisco Bay Region, Bull. Seismol. Soc. Am. 89, 764-784.

Boore, D.M, W.B. Joyner and T.E. Fumal (1997), Equations for Estimating Horizontal Response Spectra and Peak Acceleration from Western North American Earthquakes: A Summary of Recent Work, Seism. Res. Let. 68, No. 1, 128-153.

Budnitz, R.J., G. Apostolakis, D.M. Boore, L.S. Cluff, K.J. Coppersmith, C.A. Cornell, and P.A.Morris (1997), Recommendations for Probabilistic Seismic Hazard Analysis: Guidance on Uncertainty and Use of Experts, Vol. 1, U.S. Nuclear Regulatory Commission, Washington, DC, NUREG/CR-6372, $256 \mathrm{p}$.

Campbell, K.W. (1997), Empirical Near-Source Attenuation Relationships for Horizontal and Vertical Components of Peak Ground Acceleration, Peak Ground Velocity, and PseudoAbsolute Acceleration Spectra., Seism. Res. Let. 68, No. 1, 154-179.

Carpenter, D.W. and R.J. Clark (1982), Seismic Studies for Seismic Hazard Assessment, Las Positas Fault Zone, in Proc. Conf. on Earthquake Hazards in the Eastern San Francisco Bay Area, California, E.W. Hart, S.E. Hirschfeld, and S.S. Schulz, eds., Calif. Div. Mines Geol. Spec. Pub. 62, 147-154.

Carpenter, D.W., J.R. Copland, A.L. Lamarre, R.S. Mateik, M.J. Taffet, and E.M. Wade (1991), Investigation of Holocene Faulting Near Closed Landfill Pit 6, Lawrence Livermore National Laboratory Site 300, Lawrence Livermore National Laboratory, Livermore, CA, UCRL-ID-106316.

Carpenter, D.W., J.J. Sweeney, P.W. Kasameyer, N.R. Burkhard, K.G. Knauss, and R.I. Shlemon (1984), Geology of the Lawrence Livermore National Laboratory Site and Adjacent Areas, Lawrence Livermore National Laboratory, Livermore, CA, UCRL-53316, $150 \mathrm{p}$.

Cornell, C.A. (1968), Engineering Seismic Risk Analysis, Bull. Seismol. Soc. Am. 58, 1583-1606.

Crane, R.C. (1995), Geologic Map of the Midway Quadrangle, California, scale 1:24,000.

Dibblee, T.W. (1980a), Preliminary Geological Map of the Cedar Mountain Quadrangle, Alameda and San Joaquin Counties, California, U.S. Geol. Surv. Open File Rep. 80-850, scale 1:24,000. 
Dibblee, T.W. (1980b), Preliminary Geological Map of the La Costa Valley Quadrangle, Alameda County, California, U.S. Geol. Surv. Open File Rep. 80-833a, scale 1:24,000.

Dibblee, T.W. (1980c), Preliminary Geological Map of the Midway Quadrangle, Alameda and San Joaquin Counties, California, U.S. Geol. Surv. Open File Rep. 80-535, scale 1:24,000.

Hart, E.W. (1981), Recently Active Strands of the Greenville Fault, Alameda, Contra Costa, and Santa Clara Counties, California, Calif. Div. Mines Geol. Open File Rep. 81-8.

Herd, D. G. (1977), Geologic Map of the Las Positas, Greenville, and Verona Faults, Eastern Alameda County, California, U.S. Geol. Surv. Open-File Rep. 77-689.

Herd, D.G. and E.E. Brabb (1980), Faults at the General Electric Test Reactor Site, Vallecitos Nuclear Center, Pleasanton, California: A Summary Review of their Geometry, Age of Last Movement, Recurrence, Origin, and Tectonic Setting and the Age of the Livermore Gravels, U.S. Geol. Surv. Administrative Rep., 77 p.

Jahns, R.H. and R.C. Harding (1982), Evaluation of the Inferred Verona Fault in the Vallecitos Valley, California (abs.), in Proc. Conf. On Earthquake Hazards in the Eastern San Francisco Bay Area, California, E.W. Hart, S.E. Hirschfeld, and S.S. Schulz, eds., Calif. Div. Mines Geol. Spec. Pub. 62, 185.

Joyner, W.B. and D.M. Boore (1982), Prediction of Earthquake Response Spectra, U.S. Geol. Surv. Open-File Rep. 82-997, 16 p.

Rice, S., E. Stephens, and C. Real (1979), Geologic Evaluation of the General Electric Test Reactor Site Vallecitos, Alameda County, California, Calif. Div. Mines Geol. Spec. Pub. $56,19 \mathrm{p}$.

Sadigh, K., C.-Y. Chang, J.A. Egan, F. Makdisi, and R.R. Youngs (1997), Attenuation Relationships for Shallow Crustal Earthquakes Based on California Strong Motion Data. Seism. Res. Let. 68, No. 1, 180-189.

Sawyer, T.L. (1998), Assessment of Contractile Deformation Rates of the Mt. Diablo Fold and Thrust Belt, Eastern San Francisco Bay Region, Northern California, Tech. Rep., National Earthquake Hazards Reduction Prog. Award No. 98-HQ-GR-1006, U.S. Geol. Surv., Reston, VA, 7 p.

Sawyer, T.L. and Unruh, J.R. (2000), Paleoseismic Investigation of the Central Greenville Fault, Eastern San Francisco Bay Region, California, Geol. Soc. Am. Abstracts and Programs 32, A-442.

Scheimer, J.F., N.R. Burkhard, and D.O. Emerson (1991), Lawrence Livermore National Laboratory Site Seismic Safety Program - Summary of Findings, Lawrence Livermore National Laboratory, Livermore, CA, UCRL-53674 Rev. 1, 11 p.

Schwartz, D.P. (2002), U.S. Geological Survey, Menlo Park, CA, personal communication (part of WG99 study, in preparation). 
Schwartz, D.P., and K.L. Coppersmith (1984), Fault Behavior and Characteristic Earthquakes from the Wasatch and San Andreas Faults, J. Geophys. Res. 89, 5681-5698.

Smith, T.C. (1981), Fault Evaluation Rep. FER-112, Calif. Div. Mines. Geol., 18 p.

Sweeney, J.J. (1982), Magnitudes of Slip Along the Greenville Fault in the Diablo Range and Corral Hollow Areas, in Proc. Conf. on Earthquake Hazards in the Eastern San Francisco Bay Area, California, E.W. Hart, S.E. Hirschfeld, and S.S. Schulz, eds., Calif. Div. Mines Geol. Spec. Pub. 62, 137-145.

Sweeney, J.J. and J.E. Springer (1981), Geology of the Southeastern Livermore Valley, Alameda County, California, Lawrence Livermore National Laboratory, Livermore, CA, UCRL53220 Rev. 1, 54 p.

Unruh, J.R. (2000), Characterization of Blind Seismic Sources in the Mt. Diablo-Livemore Region, San Francisco Bay Area, California, Final Tech. Rep., National Hazards Reduction Prog. Award No. 99-HQ-GR-0069, U.S. Geol. Surv., Menlo Park, CA, 30 p.

Unruh, J.R., and T.L. Sawyer (1997), Assessment of Blind Seismogenic Sources, Livermore Valley, Eastern San Francisco Bay Region, Final Tech. Rep., National Earthquake Hazards Reduction Prog. Award No. 1434-95-G-2611, U.S. Geol. Surv., Reston, VA, 88 p.

Unruh, J.R., and T.L. Sawyer (1998), Paleoseismic Investigation of the Northern Greenville Fault, Eastern San Francisco Bay Area, California, Final Tech. Rep., National Hazards Reduction Prog. Award No. 1434-HQ-97-GR-03146, U.S. Geol. Surv., Menlo Park, CA, $34 \mathrm{p}$.

Working Group on California Earthquake Probabilities (2002), Earthquake Probabilities in the San Francisco Bay Region: 2002-2031, U.S. Geol. Surv., Menlo Park, CA, in preparation.

Wright, R.H., D.H. Hamilton, T.D. Hunt, M.L. Traubenik, and R.L. Schlemon (1982), Character and Activity of the Greenville Structural Trend, in Proc. Conf. on Earthquake Hazards in the Eastern San Francisco Bay Area, California, E.W. Hart, S.E. Hirschfeld, and S.S. Schulz, eds., Calif. Div. Mines and Geol. Spec. Pub. 62, 187-196.

Zhou, Y.Z., K.C. McNally, and T. Lay (1993), Analysis of the 1986 Mt. Lewis, California, Earthquake: Preshock Sequence-Mainshock-Aftershock Sequence, Phys. Earth Planetary Interiors 75, 267-288. 






$$
1
$$

